\title{
Observable, low-order dynamical controls on thresholds of the Atlantic meridional overturning circulation
}

Article

Accepted Version

Wood, R. A., Rodríguez, J. M., Smith, R. S., Jackson, L. C. and Hawkins, E. (2019) Observable, low-order dynamical controls on thresholds of the Atlantic meridional overturning circulation. Climate Dynamics, 53 (11). pp. 6815-6834. ISSN 0930-7575 doi: https://doi.org/10.1007/s00382-019-04956-1 Available at https://centaur.reading.ac.uk/87278/

It is advisable to refer to the publisher's version if you intend to cite from the work. See Guidance on citing.

To link to this article DOI: http://dx.doi.org/10.1007/s00382-019-04956-1

Publisher: Springer

All outputs in CentAUR are protected by Intellectual Property Rights law, including copyright law. Copyright and IPR is retained by the creators or other copyright holders. Terms and conditions for use of this material are defined in the End User Agreement.

www.reading.ac.uk/centaur 
Central Archive at the University of Reading

Reading's research outputs online 
Observable, low-order dynamical controls on thresholds of the Atlantic

Meridional Overturning Circulation

4

5

6

7 Richard A. Wood ${ }^{1}$, José M. Rodríguez ${ }^{1}$, Robin S. Smith ${ }^{2}$, Laura C. Jackson ${ }^{1}$ and 8

Ed Hawkins $^{2}$

9

10

11

31 Corresponding author: Richard Wood

32 Email: richard.wood@metoffice.gov.uk

33 Telephone: +44(0)1392 886641

34 ORCID: 0000-0002-3960-9513 


\section{Abstract}

37 We examine the dynamics of thresholds of the Atlantic Meridional Overturning Circulation

38 (AMOC) in an Atmosphere-Ocean General Circulation Model (AOGCM) and a simple box

39 model. We show that AMOC thresholds in the AOGCM are controlled by low-order dynamics

40 encapsulated in the box model. In both models, AMOC collapse is primarily initiated by the

41 development of a strong salinity advection feedback in the North Atlantic.

42 The box model parameters are potentially observable properties of the unperturbed (present

43 day) ocean state, and when calibrated to a range of AOGCM states predict (within some

44 error bars) the critical rate of fresh water input $\left(H_{\text {crit }}\right)$ needed to turn off the AMOC in the

45 AOGCM. In contrast, the meridional fresh water transport by the MOC ( $M_{O V}$, a widely-used

46 diagnostic of AMOC bi-stability) on its own is a poor predictor of $H_{\text {crit. }}$

47 When the AOGCM is run with increased atmospheric carbon dioxide, $H_{\text {crit }}$ increases. We use

48 the dynamical understanding from the box model to show that this increase is due partly to

49 intensification of the global hydrological cycle and heat penetration into the near-surface

50 ocean, both robust features of climate change projections. However changes in the gyre

51 fresh water transport efficiency (a less robustly modelled process) are also important.

52

53 Key Words

54 Atlantic Meridional Overturning Circulation

55 Thresholds

56 Climate Change

57 Dynamics

58 Fresh water 
60

61

62

63

64

65

66

67

68

69

70

71

72

73

74

75

76

77

78

79

80

81

82

83

84

85

86

87

88

89

90

91

92

93

94

95

\section{Introduction}

The Atlantic Meridional Overturning Circulation (AMOC) plays an important role in the climate of the Northern hemisphere through its transport of heat into the North Atlantic (Bryden and Imawaki 2001, Vellinga and Wood 2002, Jackson et al. 2015). Stommel (1961) identified the AMOC's potential to have multiple stable states, due to a simple salinity advection feedback mechanism. Beyond a certain threshold in the freshwater forcing of the North Atlantic, the AMOC becomes unsustainable and collapses. If freshwater forcing then returns to below the threshold value, the $A M O C$ does not restart. If the AMOC were close to such a threshold, a small additional freshwater input to the Atlantic (e.g. from accelerated melting of the Greenland ice sheet) could trigger AMOC collapse (Fichefet et al. 2003).

Such theoretical AMOC behaviour has been demonstrated in a range of models, including more complex box models (e.g. Rahmstorf 1996, Lucarini and Stone 2005), intermediate complexity climate models (e.g. Rahmstorf et al. 2005, Lenton et al. 2007) and ocean general circulation models (GCMs) (Rahmstorf 1996, Dijkstra 2007, Hofmann and Rahmstorf 2009). It has also been proposed to be relevant to a number of transitions seen in the palaeoclimatic record (e.g. Alley 2003). Evidence of similar behaviour has been seen in some coupled atmosphere-ocean GCMs (AOGCMs) (Manabe and Stouffer 1988, Mikolajewicz et al. 2007), but due to computational constraints a full AMOC hysteresis curve has to date only been calculated for one, low resolution AOGCM (FAMOUS) for conditions of pre-industrial atmospheric carbon dioxide $\left(\mathrm{CO}_{2}\right)$ (Hawkins et al. 2011, hereafter $\left.\mathrm{H} 11\right)$. In $\mathrm{H} 11$ and many previous studies using simpler models, the thresholds are explored through a 'hosing' experiment in which a standard model equilibrium state is perturbed by adding an extra source of fresh water, $H$, to the North Atlantic. The strength of the hosing $H$ is increased very slowly, with the aim of allowing the model to adjust towards its equilibrium state for each value of $H$. Hence a model run of several thousand years is required, and even then as shown in $\mathrm{H} 11$ a full equilibrium is not reached. Typically in such experiments, once $H$ passes a critical value $H_{\text {crit }}$ the AMOC collapses. $H$ is then slowly reduced again, but in general the AMOC does not recover when $H$ crosses back below $H_{\text {crit. }}$. Instead AMOC recovery occurs at a lower (or even negative) value of $H$, giving a hysteresis in the AMOC strength and a range of values of $H$ for which the AMOC is bistable (both strong and weak/reversed AMOC states are possible). Recently Jackson et al. (2017, hereafter J17) have analysed the detailed dynamics of the AMOC thresholds seen in the $\mathrm{H} 11$ study, showing that the salinity budget of the North Atlantic can be used to understand the dynamics of the thresholds. 
The region of $H$ values for which two stable states exist is bounded by bifurcation points beyond which either only the strong AMOC (small or negative $H$ ), or only the weak AMOC state (large $H$ ) is sustainable. Many studies have pointed to the importance of the fresh water budget of the Atlantic basin (north of $34^{\circ} \mathrm{S}$ ) in determining the bistable region, and in particular the importance of the fresh water transport across $34^{\circ} \mathrm{S}$ due to the AMOC itself (denoted here by $M_{\mathrm{OV}}$, deVries and Weber 2005, Drijfhout et al 2011). If $M_{O V}<0$ there is a positive salinity advection feedback in which negative anomalies in the AMOC induce a freshening of the Atlantic basin and hence further AMOC weakening. It has been suggested that current AOGCMs are biased towards an over-stable AMOC, due to a common positive bias in Mov (e.g. Weber et al. 2007, Valdes 2010, Mecking et al. 2017). However Sijp (2012) pointed out that other feedbacks, specifically anomalous fresh water transports due to advection of salinity anomalies by the mean AMOC $\left(<q>S^{\prime}\right)$ and the gyre/eddy components, are always stabilising, so $M_{O V}<0$ is not a sufficient condition for instability. It is therefore likely that the location of AMOC thresholds or bifurcation points is not simply determined by $M_{O V}$, but by a more complex set of feedbacks involving the fresh water budget of the Atlantic or North Atlantic basins. Recently Cheng et al (2018) have shown that in two AOGCM control runs the salinity advection feedback is not the dominant factor in variability of the North Atlantic AMOC, again emphasising the more complex nature of the processes controlling AMOC dynamics.

To quantify how far the AMOC is from a threshold, based on AOGCM hosing results, would require a wider range of $A O G C M$ runs than is currently possible, although advances in computational power are beginning to enable a more thorough investigation of thresholds in current generation climate models including eddy-permitting ocean components (Jackson and Wood 2018). Dijkstra et al (2004) propose an alternative approach involving energetic analysis of the discrete GCM equations; however this involves a very large matrix inversion problem which is also likely to present computational challenges as model resolution and complexity increase. In this study we explore a new approach to quantifying AMOC thresholds: we hypothesise that AMOC thresholds are controlled by low-order dynamical processes which are quantitatively captured by a simple but physically-based box model. The box model structure is motivated by well-established understanding of the leading order water mass structure of the current AMOC. The crucial novelties of this model, compared to previous AMOC box models, are that the model is designed to represent a physically closed global circulation/water mass system, and that the model's control parameters can be simply determined from observable, large-scale properties of the present day $(H=0)$ ocean state. Hence the box model cannot be 'tuned' to have a particular threshold - rather it is calibrated to the $H=0$ ocean state and predicts where the threshold $H_{\text {crit }}$ will lie. To test the chosen 
dynamics of the box model we calibrate it to the unperturbed ocean state simulated using

134 the FAMOUS AOGCM of $\mathrm{H} 11$ and $\mathrm{J} 17$. We demonstrate that the box model captures the

135 leading mechanisms in the threshold dynamics of FAMOUS, as analysed by J17, particularly

136 well for the first ('ramp-up') threshold in the hosing experiment described above. The box

137 model dynamics are in this sense traceable to those of the AOGCM. Our calibration method

138 implies that the present day ocean state contains sufficient information to determine the

139 threshold hosing $H_{\text {crit }}$ (to within errors which we quantify). We test this claim by repeating the

$140 \mathrm{H} 11$ hosing experiment using a modified version of the AOGCM and various atmospheric

$141 \mathrm{CO}_{2}$ concentrations, yielding various values of $H_{\text {crit }}$. We calibrate the box model to the

142 various baseline $(H=0)$ AOGCM states and test its ability to predict the different values of

$143 H_{\text {crit. }}$

145 The box model also provides a simple diagnostic framework that allows us to identify the key

146 processes and ocean properties that determine the position of the AMOC threshold over a

147 range of modelled states, and so acts as an 'emergent constraint' (e.g. Hall and Qu 2006,

148 Cox et al. 2018), allowing the threshold position to be estimated by calibrating the box model

149 to present day observations. Here (Section 6) we calibrate the box model to a data-

150 assimilating ocean reanalysis to provide a preliminary estimate of $H_{\text {crit }}$ for the present day

151 ocean. However a more in-depth analysis would be needed to generate a robust estimate

152 including error bars.

153

154 The question of whether increasing greenhouse gases will bring the AMOC closer to a

155 threshold has not to date been directly addressed using AOGCMs. Schneider et al. (2007)

156 concluded from a variety of studies (including expert elicitations) that increasing greenhouse

157 gases will increase the likelihood of substantial AMOC responses. Drijfhout et al. (2011)

158 studied the response of $M_{\mathrm{OV}}$ to increasing greenhouse gases, finding a complex response

159 with Mov generally decreasing and the strongest change at medium levels of greenhouse

160 gas increase; however it is not clear whether $M_{O V}$ has a close relationship to the threshold

161 position, and they did not calculate the changes in AMOC thresholds explicitly. Here we

162 directly calculate the AMOC hysteresis curve in FAMOUS, for a climate state with increased

163 atmospheric $\mathrm{CO}_{2}$. We find that for this AOGCM the amount of freshwater $\mathrm{H}_{\text {crit }}$ needed to

164 provoke AMOC collapse is greater with elevated $\mathrm{CO}_{2}$. This change is reproduced by the box

165 model when we calibrate it to the higher $\mathrm{CO}_{2} \mathrm{AOGCM}$ state. We then use the dynamical

166 understanding provided by the box model to assess whether this change is likely to be

167 robust or merely an artefact of the particular AOGCM used. 
Section 2 provides a brief description of the FAMOUS AOGCM, introduces the box model, and explains how the box model parameters are calibrated to the AOGCM state. Section 3 explores the processes behind AMOC thresholds in the AOGCM and box model, showing

172 that the box model captures the essential dynamics of the AOGCM thresholds to within

173 quantifiable errors. Section 4 explores the sensitivity of the AMOC collapse threshold to box model parameters, pointing to key features of the ocean state that determine the threshold position, and uses this insight to understand why $\mathrm{H}_{\text {crit }}$ increases under increased $\mathrm{CO}_{2}$ in FAMOUS. Section 5 discusses limitations of the traceability between the box model and AOGCM. Section 6 draws together the results and discusses their implications for monitoring and early warning of AMOC thresholds, and the likely implications of climate change for future AMOC stability.

\section{Model descriptions}

182

\subsection{The AOGCM}

FAMOUS (Smith et al. 2008, Smith 2012) is a coarse resolution AOGCM based on the widely used HadCM3 model (Gordon et al. 2000). The atmospheric component has a horizontal resolution of $5^{\circ} \times 7.5^{\circ}$ with 11 vertical levels, while the ocean has a horizontal resolution of $2.5^{\circ} \times 3.75^{\circ}$ with 20 vertical levels. The model provides a three-dimensional simulation of atmosphere and ocean, with physically detailed representations of processes such as clouds, precipitation and atmosphere-ocean feedbacks. FAMOUS does not employ artificial flux adjustments, which are known to distort the AMOC hysteresis behaviour (Marotzke and Stone 1995, Dijkstra and Neelin 1999). We use two versions here: the first ['XDBUA', Smith et al. 2008, hereafter FAMOUS ${ }_{A}$ ] is the version used by $\mathrm{H} 11$, while the second is an updated version including a range of minor changes [version 'XFXWB', Smith 2012, hereafter FAMOUS $S_{B}$. These model changes result in a change in the position of the AMOC threshold, and will provide an additional test of our model hierarchy.

\subsection{The box model}

198 Our box model is represented in Figure 1a. Its five boxes represent large contiguous regions 199 of the global ocean, corresponding to large scale water mass structures (Talley et al 2011) 200 (Figure 1b): the ' $T$ ' box represents the Atlantic thermocline; the ' $N$ ' box the North Atlantic 201 Deep Water (NADW) formation region and Arctic; the 'B' box the southward propagating NADW and its upwelling in the Southern Ocean as Circumpolar Deep Water; the ' $S$ ' box fresh Southern Ocean near-surface waters and their return into the Atlantic as Antarctic Intermediate Water; and the 'IP' box the Indo-Pacific thermocline. The boxes are connected by pipes of negligible volume that carry the flow. The flow is separated into a 'cold water 
206 path' (CWP), representing AMOC return flow via the South Pacific and Drake Passage, and

207 a 'warm water path' (WWP), representing AMOC return via the Indo-Pacific thermocline and

208 Agulhas leakage.

209

210 The box model physics is governed by salt conservation in each box, and a linear

211 dependence of the overturning circulation on the density difference of the North Atlantic and

212 Southern Ocean boxes:

213

214

$$
q=\lambda\left[\alpha\left(T_{S}-T_{N}\right)+\beta\left(S_{N}-S_{S}\right)\right]
$$

215

216

where $q$ is the AMOC flow and $\lambda$ is a constant. A linear equation of state is used, with thermal and haline coefficients $\alpha=0.12 \mathrm{kgm}^{-3} \mathrm{~K}^{-1}$ and $\beta=0.79 \mathrm{kgm}^{-3}(p s u)^{-1} . T$ and $S$ denote mean temperature and salinity over the boxes. Such a relationship has previously been demonstrated in a range of models (e.g. Hughes and Weaver 1994, Rahmstorf 1996, Thorpe et al 2001, Sijp 2012), and we find it holds in our FAMOUS runs over the entire hysteresis loop described below (Figure 2a), justifying its use in our box model a posteriori.

223 The salinities of the five boxes are governed by salt conservation:

$q \geq 0:$

$$
\begin{gathered}
V_{N} \frac{\mathrm{d} S_{N}}{\mathrm{~d} t}=q\left(S_{T}-S_{N}\right)+K_{N}\left(S_{T}-S_{N}\right)-F_{N} S_{0} \\
V_{T} \frac{\mathrm{d} S_{T}}{\mathrm{~d} t}=q\left[\gamma S_{S}+(1-\gamma) S_{I P}-S_{T}\right]+K_{S}\left(S_{S}-S_{T}\right)+K_{N}\left(S_{N}-S_{T}\right)-F_{T} S_{0} \\
V_{S} \frac{\mathrm{d} S_{S}}{\mathrm{~d} t}=\gamma q\left(S_{B}-S_{S}\right)+K_{I P}\left(S_{I P}-S_{S}\right)+K_{S}\left(S_{T}-S_{S}\right)+\eta\left(S_{B}-S_{S}\right)-F_{S} S_{0} \\
V_{I P} \frac{\mathrm{d} S_{I P}}{\mathrm{~d} t}=(1-\gamma) q\left(S_{B}-S_{I P}\right)+K_{I P}\left(S_{S}-S_{I P}\right)-F_{I P} S_{0} \\
V_{B} \frac{\mathrm{d} S_{B}}{\mathrm{~d} t}=q\left(S_{N}-S_{B}\right)+\eta\left(S_{S}-S_{B}\right)
\end{gathered}
$$


$q<0$ :

$$
\begin{gathered}
V_{N} \frac{\mathrm{d} S_{N}}{\mathrm{~d} t}=|q|\left(S_{B}-S_{N}\right)+K_{N}\left(S_{T}-S_{N}\right)-F_{N} S_{0} \\
V_{T} \frac{\mathrm{d} S_{T}}{\mathrm{~d} t}=|q|\left(S_{N}-S_{T}\right)+K_{S}\left(S_{S}-S_{T}\right)+K_{N}\left(S_{N}-S_{T}\right)-F_{T} S_{0} \\
V_{S} \frac{\mathrm{d} S_{S}}{\mathrm{~d} t}=\gamma|q|\left(S_{T}-S_{S}\right)+K_{I P}\left(S_{I P}-S_{S}\right)+K_{S}\left(S_{T}-S_{S}\right)+\eta\left(S_{B}-S_{S}\right)-F_{S} S_{0} \\
V_{I P} \frac{\mathrm{d} S_{I P}}{\mathrm{~d} t}=(1-\gamma)|q|\left(S_{T}-S_{I P}\right)+K_{I P}\left(S_{S}-S_{I P}\right)-F_{I P} S_{0} \\
V_{B} \frac{\mathrm{d} S_{B}}{\mathrm{~d} t}=\gamma|q| S_{S}+(1-\gamma)|q| S_{I P}-|q| S_{B}+\eta\left(S_{S}-S_{B}\right)
\end{gathered}
$$

227

228

229

230

231

232

233

234

235

236

241

242

243

244

245

246

247

where $V_{i}$ is the volume of box $i, \gamma$ denotes the proportion of the cold water path, and $\eta$ is a S$B$ box mixing parameter, representing mixing of NADW with fresher waters as it passes around the global circulation. Oceanographically $\eta$ represents the mixing of Circumpolar Deep Water with fresher surface water masses in the Southern Ocean (Talley et al. 2011). Wind driven salinity transports between boxes are represented by a diffusive flux with coefficients $K_{N}, K_{S}, K_{I P}$ associated with the gyre strengths.

The box volumes $V_{i}$, gyre coefficients $K_{i}$, surface freshwater fluxes $F_{i}$, along with $\lambda, \eta$ and $V$ are specified, time-invariant parameters. $S_{0}$ is a reference salinity set to 0.035 . We assume that the mean temperature $T_{N}$ of the North Atlantic box increases linearly with AMOC strength, reflecting the role of the AMOC in transporting heat into the North Atlantic:

$$
T_{N}=\mu q+T_{0}
$$

The other box temperatures are fixed. While not as tight as the $q v s$. density relationship (1) over the whole hysteresis loop, there is nonetheless a close linear relationship between $q$ and $T_{N}$, over the portion of the curve between the un-hosed state and the first threshold crossing, which is the part of the experiment which we will focus on in our analysis below (Figure 2b). We found empirically that allowing for this variation in $T_{N}$ slightly increases the sharpness of the transition to the off state near the threshold, but temperature variations only 
play a minor role in density variations in these experiments (Figure 4a) and there is little sensitivity of $H_{\text {crit }}$ to the value of $\mu$ (see discussion in Section 4.1). A more sophisticated treatment of temperature effects would be needed for thermally driven scenarios such as the response of the $\mathrm{AMOC}$ to transient global warming.

Our model adopts a similar broad approach to the box model of Rahmstorf (1996), but with several important additions:

i. Our model is designed to achieve a degree of quantitative, as well as qualitative agreement with corresponding AOGCM experiments. For this reason our boxes represent contiguous regions that span the majority of the global ocean, and are assigned different volumes that are identified with the largest scale water masses;

ii. The choice of separate $\mathrm{N}$ and $\mathrm{B}$ boxes was partly driven by the desire for quantitative comparison with the AOGCM: in an earlier prototype of the model where the $\mathrm{N}$ and $\mathrm{B}$ boxes were merged, the relationship between the density difference and MOC strength (Fig. 2a) was less tight, leading to large quantitative errors in the hysteresis loop. In the Rahmstorf model the B box (Rahmstorf's Box 4) is essentially passive and isolated $\left(S_{4}=S_{2}\right.$ at equilibrium), whereas here we allow for mixing between the $B$ box and the surface ocean ( $\mathrm{S}$ box);

iii. Our model explicitly represents a closed global circulation and its associated fresh water transports, including the different roles of the cold and warm water paths. In contrast, in the Rahmstorf 1996 model the closure of the MOC outside the Atlantic basin (Rahmstorf's Box 1), and the role of gyre transports, must be specified through the concept of a fixed 'active fresh water flux' which is hard to associate with a specific observable quantity and does not respond to the evolving salinity fields. The additional physics in our model allows it to generate self-consistent solutions that can be identified with physical variables.

Our representation of the WWP/CWP has limitations: due to the large extent of the IP box the water coming back into the Atlantic basin through the WWP is not as saline as the real Agulhas return flow. Therefore our model may underestimate the importance of the WWP/CWP parameter $\gamma$. We note that for the parameter values studied here, variations in $S_{S}$ and $S_{B}$ are small compared to the other boxes. This means that a 3-box reduction of the model (with $S_{S}$ and $S_{B}$ fixed) is possible that contains the essential dynamical behaviour of the 5-box model in the most relevant parameter ranges, at the cost of some quantitative fidelity. Even the 3-box reduction has one extra degree of freedom compared with the Stommel 1961 and Rahmstorf 1996 models, allowing a much richer dynamical structure 
including homoclinic and Hopf bifurcations in addition to the saddle-node bifurcations that are seen in the simpler models (Alkhayuon et al. 2019).

Our model has several similarities to the model of Johnson et al (2007), which showed how more recent theories of the AMOC which emphasise closure of the potential energy budget through Southern Ocean winds and interior diapycnal mixing (e.g. Gnanadesikan 1999) can be reconciled with salinity-budget considerations and bistability as emphasised by the Stommel (1961) model. However our model differs from that of Johnson et al. 2007 in that we do not attempt to parametrise the processes that determine the transformation of NADW to cold, fresh Antarctic Intermediate Water or warm, salty thermocline water, and then solve for the pycnocline structure and AMOC. Instead in our model these transformations, and the basic geometry of the water masses are to some extent prescribed through the model parameters and the specified box boundaries. Our emphasis is on describing the dynamical mechanisms that occur when the AMOC passes from a strong ('on') state to a weak or reversed state (i.e. when the current strong AMOC state becomes unsustainable), on demonstrating that the box model dynamics accurately describe the dynamics of this transition in the AOGCM, and on identifying observable properties of the ocean circulation that determine where the transition lies.

\subsection{Calibration of the box model to the AOGCM}

To calibrate the box model to a GCM such as FAMOUS we use decadal mean variables diagnosed purely from large scale properties of the GCM's unperturbed equilibrium state (red dot in Figure 3c), without knowledge of the GCM's response to hosing. First, box boundaries are chosen to reflect approximate water mass boundaries in the GCM salinity field (Figure 1b). Once the box volumes are fixed, all but one of the control parameters of the box model can be diagnosed from emergent properties of FAMOUS (box average temperature and salinity, surface fluxes and section freshwater transports), and so could also in principle be diagnosed from observations. Box mean salinities, temperature and surface fresh water fluxes are obtained directly from the GCM. $K_{N}, K_{S}$ and $K_{I P}$ are determined by diagnosing the gyre salt transport $M$ in the GCM across the corresponding box boundaries:

$$
K_{i j}=(M \times 1000) / \rho_{0}\left(S_{i}-S_{j}\right)
$$

where $\rho_{0}$ is the mean seawater density. The $\mathrm{K}_{\mathrm{ij}}$ above are in units of $\mathrm{m}^{3} \mathrm{~s}^{-1}, M$ in $\mathrm{kg} \mathrm{s}^{-1}$ and the salinities in psu. 
321 The flow constant $\lambda$ is calculated from (1), after diagnosing $q$ from the GCM as the maximum

322 of the Atlantic overturning streamfunction at $30^{\circ} \mathrm{S}$.

323

324 The parameters $\mu$ and $T_{0}$ are calibrated by comparison with the North Pacific, a basin

325 without a strong overturning circulation: we diagnose $T_{0}$ as the mean oceanic temperature of

326 a full-depth box covering the North Pacific and choose $\mu$ to balance (12) using the diagnosed

327 values of $T_{N}$ and $q$. Finally $\mathrm{\gamma}$, the proportion of the return AMOC flow carried by the cold

328 water path, is chosen in the range $0 \leq \gamma \leq 1$ to optimise the model fit to the box average

329 salinities in the GCM control state. We find $y$ in the range 0.39 to 0.85 in the cases

330 considered here, somewhat larger than the values diagnosed directly from ocean GCMs by

331 Döös (1995) and Speich et al. (2001). The sensitivity of the AMOC threshold to $Y$ is

332 discussed in Section 4. In this paper we calibrate the box model to a number of AOGCM

333 states, discussed below. The resulting parameter values are shown in Table 1.

\section{AMOC thresholds in the GCM and box model}

\subsection{Dynamics of the hysteresis}

340 The AMOC hysteresis structure and thresholds were assessed in FAMOUS $_{A}$ in a series of

341 'hosing' experiments by [H11]. A freshwater flux $H$ was artificially applied to the North

342 Atlantic surface between $20^{\circ} \mathrm{N}-50^{\circ} \mathrm{N}$. The same flux was removed uniformly from the rest

343 of the ocean surface to conserve global salinity. The AMOC response is sensitive to the

344 region to which $H$ is applied (Smith and Gregory 2009), and other regions may be more

345 appropriate if the goal were to simulate, say, additional fresh water discharge from the

346 Greenland Ice Sheet (Swingedouw et al. 2015, Bakker et al. 2016). However our focus here

347 is on elucidating the dynamics of the AMOC thresholds so we stick to a single region of

348 application for consistency with the existing AOGCM experiment.

$H$ was gradually increased at a rate of $5 \times 10^{-4} \mathrm{~Sv} /$ year $\left(1 \mathrm{~Sv}=10^{6} \mathrm{~m}^{3} \mathrm{~s}^{-1}\right)$, allowing the AMOC to adjust towards equilibrium with the hosing at any time. When $H$ reached 1 Sv (after 2000 years), it was gradually reduced until it reached $-0.4 \mathrm{~Sv}$. In the period of increasing hosing, the AMOC collapsed when $H$ reached about $0.55 \mathrm{~Sv}$ (Figure 3c, dotted curve). When $H$ was reduced, the AMOC stayed collapsed, only recovering once $H$ became less than about -0.1 Sv. 
357 Even though $H$ is increased and decreased slowly, the experiments do not capture fully 358 equilibrated $\mathrm{AMOC}$ solutions. This was shown in $\mathrm{H} 11$, which demonstrated that the region of

359 bistable equilibrium solutions in $\mathrm{FAMOUS}_{\mathrm{A}}$ is narrower than the hysteresis region that 360 appears in response to the slow increase then decrease of $H$. However in what follows we 361 adopt a pragmatic definition of the 'AMOC threshold' as the value $H_{\text {crit }}$ of the additional 362 freshwater flux $H$ when the AMOC strength first reaches zero in the 'ramp-up' phase of the 363 experiment (see dashed lines in Figure 3c). Further discussion of the response of the box model to time-varying $H$, including rate-dependent tipping responses, can be found in Alkhayuon et al. (2019).

The dynamics driving the AMOC thresholds in $\mathrm{FAMOUS}_{\mathrm{A}}$ are captured by the simple physics of the box model. When the same hosing experiment is performed with the box model calibrated to FAMOUS ${ }_{A}$, box-average salinities in the regions represented by the box model evolve similarly in FAMOUS $_{A}$ and the box model (Figure 3a,b). The box model's AMOC shows hysteresis similar to that in $\mathrm{FAMOUS}_{\mathrm{A}}$ (Figure 3c), collapsing at a similar hosing value $(0.48 \mathrm{~Sv})$. Together the salinities and AMOC in the box model represent its full state vector.

373 This strongly suggests that the dynamics of AMOC hysteresis in the AOGCM are described to leading order by the dynamics of the box model. This will be confirmed below by a comparison of the box model dynamics with the detailed analysis of the FAMOUS ${ }_{A}$ run by J17.

We note that our measure of the AMOC in AOGCMs is the maximum (negative value) of the overturning streamfunction at $30^{\circ} \mathrm{S}$, which has been proposed as the key latitude at which the salinity advection feedback operates (e.g. Rahmstorf 1996, Drijfhout et al. 2011), rather than taking the maximum over the whole Atlantic, or around $30^{\circ} \mathrm{N}$, as used by many previous studies. This explains why the $\mathrm{FAMOUS}_{\mathrm{A}} \mathrm{AMOC}$ is negative in the collapsed state in Figure 3, rather than close to zero as shown in $\mathrm{H} 11$ and $\mathrm{J} 17$ (whose Figure 5a shows the maximum streamfunction at $26^{\circ} \mathrm{N}$ ). The collapsed state in $\mathrm{FAMOUS}_{\mathrm{A}}$ has a reverse overturning cell that is largely confined to the South Atlantic and so not seen in the streamfuction at $26^{\circ} \mathrm{N}$ (see J17 Figure $3 \mathrm{c}$ or H11 Figure1). The use of $30^{\circ} \mathrm{S}$ gives a tighter and more linear relationship between the density difference and the AMOC (compare Figure 2a with Figure $5 \mathrm{a}$ of $\mathrm{J} 17$, which defines the $\mathrm{AMOC}$ at $26^{\circ} \mathrm{N}$ ), and the relationship passes through the origin, whereas if $26^{\circ} \mathrm{N}$ were used an offset would need to be added to Equation (1) to obtain a good fit (J17), and it would be hard to calibrate the offset from the un-hosed state alone. The threshold values of $H$ diagnosed for the AOGCM do not differ much whether either latitude is used (compare Figure $3 c$ with Figure $2 a$ of $J 17$ ). 
The agreement between box model and AOGCM is particularly good in the initial 'ramp-up' part of the hosing experiment, up to the point where the right-hand threshold is crossed (after about 1100 years, Figure 3), although the decline of the AMOC as $H$ is increased is more gradual in the box model. We show in Section 5.3 below that the more gradual AMOC decline in the box model is a consequence of the limited vertical resolution of the box model, with surface fluxes being distributed over the full depth of the boxes. Once the collapsed AMOC state is established, changes in AOGCM water mass structure (see $\mathrm{J} 17$ ) result in larger quantitative differences between the box model and AOGCM solutions. We discuss these differences briefly in Section 5.2 , but our focus in this paper is primarily on the 'rampup' stage and the right-hand threshold, as this is the most relevant for assessing the resilience of the current $\mathrm{AMOC}$.

\subsection{Detailed dynamics of the 'ramp-up' threshold}

The AMOC threshold behaviour in the $\mathrm{FAMOUS}_{\mathrm{A}}$ experiment has been analysed in detail by $\mathrm{J} 17$, in terms of the salinity budget of the North Atlantic/Arctic from $40^{\circ}-90^{\circ} \mathrm{N}$, the same region as the $\mathrm{N}$ box in our box model calibration. AMOC changes in $\mathrm{FAMOUS}_{\mathrm{A}}$ are driven primarily by changes in the salinity component of density in this region. We therefore compare here the salinity budget of the $\mathrm{N}$ box (equations 2 and 7 ) with the corresponding budget in $\mathrm{FAMOUS}_{\mathrm{A}}$ from $\mathrm{J17}$, as the right-hand threshold is crossed, to obtain a more detailed understanding of how well the box model captures the threshold dynamics of the AOGCM ${ }^{1}$. Having demonstrated very similar dynamics in the box model and AOGCM we exploit the simplicity of the box model to gain further insight into the threshold dynamics.

Figure $4 a$ shows terms in the $\mathrm{N}$ box salinity budget for FAMOUS $_{\mathrm{A}}$, during the 'ramp up' part of the experiment, adapted from J17. During most of the ramp-up phase the North Atlantic freshens slowly in response to the increasing hosing (red). However the freshening is partly offset by increasing salinification due to advection by the gyre component of the flow, which transports the fresh anomalies out across $40^{\circ} \mathrm{N}$ (blue). Advection by the overturning component of the flow (green) is remarkably constant for most of the ramp-up phase. However as the threshold is approached (from about 800 years into the run) two factors act to accelerate the freshening. First, atmospheric feedbacks act to increase the surface fresh water flux into the North Atlantic (seen as a slight increase in the slope of the red line in Figure $4 \mathrm{a}$ from about $\mathrm{t}=800$ years), attributed by $\mathrm{J} 17$ to a spinup of the Pacific MOC and

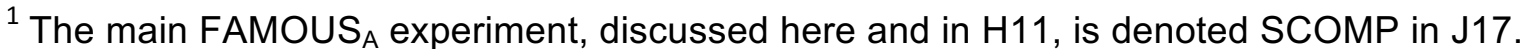

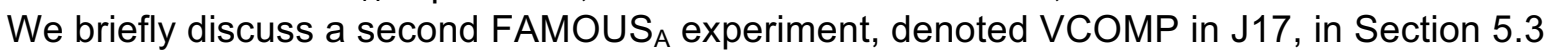
below.
} 
consequent increase in inter-basin atmospheric water transport. Secondly a strong salinity

428 advection feedback begins to operate, leading to a rapid decrease in the salinity advection

429 by the overturning component of the flow (green line). These two processes lead to rapid

430 freshening of the North Atlantic and collapse of the AMOC. The box model does not include

431 the atmospheric feedback on fresh water fluxes since its surface fresh water flux is fixed. So

432 the question arises whether this atmospheric feedback plays a critical qualitative or

433 quantitative role in the AMOC threshold. Figure 4a suggests that the atmospheric feedback

434 (which can be seen more clearly in Figure 6e of $\mathrm{J17}$ ) is relatively small.

435

436 Figure $4 \mathrm{~b}$ shows the corresponding salinity budget terms for the box model. We see

437 quantitatively similar behaviour to $\mathrm{FAMOUS}_{\mathrm{A}}$ for all the budget terms, in the first 800 years.

438 The salinity advection by the overturning is again roughly constant. From year 800 , the box

439 model surface fluxes do not include the atmospheric feedback described for FAMOUS $_{A}$

440 above. However the salinity advection by the MOC does decrease from this point in the box

441 model just as in FAMOUS , leading to AMOC collapse. Hence the atmospheric feedback

442 identified by $\mathrm{J} 17$ does not appear to be an essential element in the AMOC collapse, which

443 instead is primarily due to the sudden collapse of the salinity advection by the MOC.

444 However the atmospheric feedback may be expected to hasten the AMOC collapse, as

445 suggested by J17. To confirm this we have rerun the box model with time-varying $F_{N}$

446 diagnosed from the FAMOUS ${ }_{\mathrm{A}}$ run; the value of $H_{\text {crit }}$ diagnosed with time-varying $F_{N}$ is 0.40

$447 \mathrm{~Sv}$, compared with $0.48 \mathrm{~Sv}$ for the constant $F_{N}$ case. The total fresh water input (hosing plus

448 increase in $F_{N}$ ) at collapse is approximately the same in both cases, suggesting that the

449 additional water input from the atmospheric feedback behaves simply as an additional

450 hosing.

451

452 To elucidate the sudden reduction in the salinity advection by the MOC, we rewrite the

453 salinity advection term in (2) by substituting for $q$ from (1) and reformulating in terms of $\left(S_{T^{-}}\right.$

$\left.454 S_{N}\right):$

455

456

$q\left(S_{T}-S_{N}\right)=\lambda\left[\alpha\left(T_{S}-T_{N}\right)+\beta\left(S_{T}-S_{S}\right)\right]\left(S_{T}-S_{N}\right)-\lambda \beta\left(S_{T}-S_{N}\right)^{2}$

457

458 Noting that over the first 800 years, salinity changes are dominated by changes in $S_{N}$ (Figure

$4593 b$ ), we can approximate $S_{T}$ and $S_{S}$ as constant over this period. As $S_{T}-S_{N}$ increases due to

460 freshening of $S_{N}$, the $-\lambda \beta\left(S_{T}-S_{N}\right)^{2}$ term eventually dominates, resulting in the eventual rapid

461 collapse of $q\left(S_{T}-S_{N}\right)$.

462 
463 Note that $-q\left(S_{T}-S_{N}\right)$, the fresh water transport by the AMOC across $40^{\circ} \mathrm{N}$ by the MOC, is the 464 equivalent at $40^{\circ} \mathrm{N}$ of the diagnostic commonly associated with AMOC stability through a 465 linear salinity advection feedback argument (often referred to as $M_{\text {OV }}$ or $F_{\text {OV }}$, e.g. Rahmstorf 466 1996, Mecking et al. 2017). We will use the notation ${ }^{L} M_{O V}$ to denote $M_{O V}$ at latitude $L$, where 467 necessary for clarity. The linear feedback argument requires ${ }^{L} M_{O V}$ to be negative at latitude $468 L$ for the salinity advection feedback to become positive/destabilising at that latitude.

469 However, as pointed out by Sijp (2012), what is important for stability is not $M_{O V}$ but $\partial M_{O V} / \partial q$; 470 positive $\partial M_{O V} / \partial q$ implies a negative (stabilising) feedback. In the initial phase (years 0-800), 471 decreases in $q$ are offset by increases in $\left(S_{T_{T}} S_{N}\right)$ as the hosing freshens the North Atlantic 472 (Figure $4 \mathrm{C}$ ). So although ${ }^{40 N} M_{O V}$ is negative in the initial state, the net salinity advection 473 feedback $\partial^{40 N} M_{O V} / \partial q$ is approximately zero until the $\left(S_{T}-S_{N}\right)^{2}$ term begins to dominate around 474 year 800 .

475

476 3.3 The 'ramp up' threshold in other AOGCM states

477 To test the ability of the box model to provide quantitative insight into the position of the 478 right-hand threshold, we have performed two new hosing experiments with FAMOUS. For 479 these we use the more recent model version FAMOUS $\mathrm{F}_{\mathrm{B}}$. The baseline state for the first new 480 experiment is the basic $\mathrm{FAMOUS}_{\mathrm{B}}$ model spun up from rest with pre-industrial $\mathrm{CO}_{2}(\mathrm{Smith}$ 481 2012), while for the second experiment $\mathrm{CO}_{2}$ is doubled from pre-industrial values and the 482 model is spun up for 920 years to adjust to the higher $\mathrm{CO}_{2}$ forcing. We then repeat the 483 hosing experiments, starting from these two new baseline states. The first of these 484 experiments is identical to the experiment of $\mathrm{H} 11$, except for the use of $F A M O U S_{B}$ rather 485 than FAMOUS $_{\mathrm{A}}$, while the second experiment, also using FAMOUS $_{\mathrm{B}}$, starts from a different 486 climate state representing a climate with increased greenhouse gas concentrations.

488 First we repeat the 'ramp up' part of the hosing experiment using FAMOUS F, with 489 preindustrial $\mathrm{CO}_{2}$. The model change from $\mathrm{FAMOUS}_{\mathrm{A}}$ to $\mathrm{FAMOUS}_{\mathrm{B}}$ results in a reduction of $490 \mathrm{H}_{\text {crit }}$ by about $0.1 \mathrm{~Sv}$ (Figure $5 \mathrm{a}$ ). This change is captured by the box model when calibrated 491 to the different climate states of the two FAMOUS versions (Figure 5b), providing further 492 confidence in the box model. The different box model parameters for the FAMOUS $_{\mathrm{A}}$ and 493 FAMOUS $_{\mathrm{B}}$ states are shown in Table 1.

As a further test of the ability of the box model to estimate $H_{\text {crit }}$ for different ocean states, we 496 have rerun the FAMOUS $_{\mathrm{B}}$ hosing experiment, but now starting from a state reached after 920 years of integration at twice preindustrial $\mathrm{CO}_{2}$. We find that around $0.35 \mathrm{~Sv}$ more freshwater input is needed to shut down the AMOC in the $2 \times \mathrm{CO}_{2}$ state, compared with the pre-industrial state (Figure 5a). The same simulation is done with the box model, re- 
calibrated to the un-hosed $2 \times \mathrm{CO}_{2}$ state of FAMOUS $\mathrm{B}$. The box model response to increased

$501 \mathrm{CO}_{2}$ is qualitatively similar to that of $\mathrm{FAMOUS}$, with $0.23 \mathrm{~Sv}$ more hosing required than in

502 the preindustrial state (Figure $5 b$ ).

503

504 Overall the box model, when calibrated to different AOGCM states, appears to provide

505 quantitative information on the value of $H_{\text {crit. }}$. This implies that large scale, emergent

506 properties of the unperturbed ocean state contain enough information to constrain $H_{\text {crit }}$. The

507 simplicity of the box model allows us to understand the key factors and processes that

508 determine $H_{\text {crit. }}$, and we pursue this in Section 4 through a set of parameter sensitivity

509 studies.

510

\section{4. Parameter sensitivity of the box model}

512

513 In this section we examine the sensitivity of the 'ramp-up' threshold $H_{\text {crit }}$ to changes in

514 individual box model parameters, and provide a physical interpretation of those sensitivities.

515 We then discuss whether the fresh water transport by the AMOC in the baseline state (MOV)

516 is a good predictor of the value of $H_{\text {crit, }}$ and assess the impact of the parameter changes

517 seen at increased $\mathrm{CO}_{2}$.

518

519

\subsection{Parameter sensitivity of the threshold}

520 Figure 6a shows the value of hosing $H_{\text {crit }}$ at which $q$ crosses zero in the ramp-up phase, as a

521 function of the various box model parameters. Each parameter is varied individually with

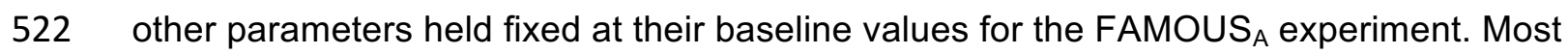

523 parameters have been set to zero, one half and two times their baseline values, except

524 where this did not make physical sense. We also varied the strength of the global

525 atmospheric water cycle by simultaneously scaling all the surface fresh water fluxes $F_{i}$ by 0.5

526 and 1.5 (thus mantaining zero global mean flux in each case).

528 The physical mechanisms of the different parameter sensitivities during the ramp-up phase

529 can be understood in terms of the analysis of the fresh water budget of the North Atlantic ( $N$

530 box) in Section 3 above. Rewriting equation (1) as

531

532

$$
q=\lambda\left[\alpha\left(T_{S^{-}} T_{0}\right)+\beta\left(S_{N}-S_{S}\right)\right] /(1+\lambda \alpha \mu)
$$

533

534 we see that the temperature driving of the flow is constant in time (and positive, Table 1).

535 Figure $3 a$ shows that the salinity driving is also initially positive $\left(S_{N}>S_{S}\right)$, and that the

536 freshening of $S_{N}$ is much greater than variations in $S_{S}$ during the ramp-up phase. As the 
537 hosing increases, $S_{N}$ eventually becomes less than $S_{S}$ (Figure $3 a$ ) and the salinity driving 538 becomes sufficiently negative to counteract the temperature driving, giving $q=0$. We use this 539 framework to interpret the parameter sensitivities in the following.

540

$541 K_{N}$ : Higher values of $K_{N}$ result in a larger $\mathrm{H}_{\text {crit. }}$ As $\mathrm{K}_{\mathrm{N}}$ increases there is an increasingly strong 542 negative feedback through salting of the $\mathrm{N}$ box by the gyre term as $S_{N}$ freshens,

543 counteracting and delaying the positive salinity advection feedback due to advection by the $544 \operatorname{MOC}\left(\lambda \beta\left(S_{T}-S_{N}\right)^{2}\right.$ in (14)). This can be seen by comparing the $\mathrm{N}$ box salinity budget in the 545 case where $K_{N}=0$ (Figure $7 a$ ) with the corresponding figure in the baseline case (Figure $4 b$ ).

546 Without the negative feedback from $K_{N}$ the salinity advection feedback is much sharper 547 (green line), leading to an earlier and more abrupt collapse of the AMOC. A similar 548 sensitivity has recently been reported in simulations of the Last Glacial Maximum using the 549 UVic intermediate complexity climate model (Muglia et al. 2018): applying the stronger North 550 Atlantic wind stress typical of the LGM (equivalent to increasing the gyre strength and hence $551 \mathrm{~K}_{\mathrm{N}}$ ) results in a stronger fresh water perturbation being required to shut down the AMOC.

552

$553 K_{S}$ : Larger values of $K_{S}$ result in a smaller $H_{\text {crit. }}$ Increasing $K_{S}$ increases $S_{S}$, and so reduces $554\left(S_{N}-S_{S}\right)$ in the un-hosed state. Hence less freshening of $S_{N}$ is needed to bring $q$ to zero.

555 This can be seen in Figure $7 \mathrm{~b}$, which shows the case with doubled $K_{S}$. The cases of doubled $556 K_{S}$ and zero $K_{N}$ (Figure $7 a$ ) therefore result in similar values of $H_{c r i t}$ but for different physical 557 reasons.

558

$K_{I P}$ : Larger values of $K_{I P}$ result in a smaller $H_{\text {crit- }}$ This sensitivity is the only one where we find 560 significant nonlinearity: it is particularly strong at low values of $K_{I P}$ because as $K_{I P}$ becomes small the only mechanism available to balance the net evaporation from the Indo-Pacific in $(5)$ is the advective flux convergence $(1-\gamma) q\left(S_{B}-S_{I P}\right)$. So as $q$ decreases $S_{I P}$ must increase rapidly to maintain the same advective flux convergence. This can be seen in the different evolution of $S_{I P}$ in runs with low and high $K_{I P}$ (Figure 8). For low $K_{I P}$, the rapid increase of $S_{I P}$ results in a negative feedback on $q$ : weakening $q$ results in saltier Indo-Pacific water, which then enters the Atlantic via the warm water path. This negative feedback from the warm water path swamps the more commonly emphasised positive salinity advection feedback (e.g. Rahmstorf 1996); the positive feedback results from advection of the mean salinity by the anomalous flow $\left(q^{\prime}<S>\right)$, whereas the negative feedback that we identify here results from advection of anomalous salinity by the mean flow ( $<q>S^{\prime}$, Sijp 2012). Advection of anomalous salinity was also found to make a significant contribution to the natural internal

572 variability of $M_{O V}$ and the AMOC in two modern AOGCMs by Cheng et al (2018). In the low $573 K_{I P}$ situation it is likely that the consequent large increase in $S_{I P}$ (Figure 8a) would result in 
changes to the Indo-Pacific circulation (e.g. the Pacific MOC, see J17), with possible oceanic or atmospheric feedbacks that are not included in the box model. So the strong sensitivity to $K_{I P}$ seen here may to some extent be an artefact of the limited Pacific Ocean and atmospheric processes in the box model.

\section{$T_{S^{-}} T_{0}$ : Larger values imply stronger temperature driving of the flow. Hence greater} freshening of $S_{N}$ (stronger hosing) is needed to before the salinity gradient is strong enough to counteract the temperature gradient in (15).

$\mu$ : In this case as $\mu$ was varied, $T_{\mathcal{S}^{-}} T_{0}$ was adjusted to keep the same value of $q$ in the baseline state. Larger values of $\mu$ imply larger values of $T_{S}-T_{0}$, and hence the same sign of sensitivity as was seen to $T_{S^{-}} T_{0 .}$. If $\mu$ is instead changed without adjusting $T_{S^{-}} T_{0}$, there is virtually no sensitivity of $H_{\text {crit }}$ to $\mu$, since the amount of North Atlantic freshening (hosing) required to bring the density gradient to zero in (15) is not directly changed. Thus the apparent sensitivity to $\mu$ is mostly due to sensitivity to the invariant part of the temperature gradient $T_{S^{-}} T_{0}$.

$\lambda$ : The sensitivity is weak because a change in $\lambda$ does not directly change the North Atlantic freshening (hosing) needed to bring the N-S density difference to zero in (15). Although increased $\lambda$ produces a stronger baseline flow, there is a balancing change in the amount that $q$ changes for a given density change.

$\eta$ : Sensitivity to $\eta$ is weak. $\eta$ effectively relaxes $S_{S}$ toward the salinity of the large deep water reservoir $S_{B}$, resulting the small variation in $S_{S}$ seen in the baseline experiment (Figure 3a). For small $\eta, S_{S}$ is free to vary more in response to advection by the changing $q$, but these salinity variations are simply advected around the CWP and cause corresponding changes in $S_{T}$ and $S_{N}$. So the overall variations in $\left(S_{N}-S_{S}\right)$ in (15) are not much different from the baseline case.

$\gamma$ : Larger values of $\gamma$ have smaller values of $H_{\text {crit. }}$ Large values of $\gamma$ imply a dominant CWP. In this case the Atlantic is fresher and the Southern Ocean saltier than in the low $\gamma$ (WWP) case. In terms of (15), $\left(S_{N}-S_{S}\right)$ begins at a lower value and so less freshening is required to reverse the density gradient.
$F_{i}:$ Here all the surface fresh water fluxes are scaled by a factor of 0.5 or 1.5 , maintaining zero global mean flux in each case. A stronger mean hydrological cycle results in a larger 
611 initial salinity difference $\left(S_{N}-S_{S}\right)$ in (15). Hence more hosing is needed to reverse the density

612 gradient, and larger fresh water fluxes result in a larger $H_{\text {crit. }}$

613

614 Overall, we see that $H_{\text {crit }}$ is sensitive to many of the box model parameters, including those

615 involving the thermohaline forcing $\left(T_{S}-T_{0}, F_{i}, \mu\right)$, and those involving wind-driven gyre

616 exchange $\left(K_{i}\right)$. It is perhaps surprising (but explained by the analysis above) that the

617 sensitivity to parameters involving internal dynamics of the $\operatorname{AMOC}(\lambda, \gamma, \eta)$ is relatively weak.

618 The parameter sensitivity is generally linear in the range considered, except for $K_{I P}$, where

619 the strong nonlinearity at low values may be a consequence of the simplicity of the box

620 model dynamics.

621

622

623

4.2 Role of the AMOC fresh water transport MOV

624 The fresh water transport into the Atlantic basin across the southern boundary of the basin

625 (around $34^{\circ} \mathrm{S}$ ) by the AMOC itself (often denoted $M_{O V}$ or $F_{O V}$ ) has been proposed as an

626 important diagnostic of AMOC bi-stability at equilibrium, with negative $M_{O V}$ implying that the

$627 \mathrm{AMOC}$ is in a bi-stable regime, and positive $M_{O V}$ implying a mono-stable AMOC (Rahmstorf

628 1996; deVries and Weber 2005; Mecking et al. 2017). Mov also plays a role in the transient

629 response of the AMOC to hosing: modifying $M_{O V}$ by applying flux adjustments at the

630 Southern boundary or throughout the Atlantic can change the response of the AMOC in

631 AOGCM hosing experiments (Cimatoribus et al. 2012, Jackson 2013, Liu et al. 2017). The

632 sign of $M_{\text {OV }}$ has been associated with the sign of the salinity advection feedback, with

633 positive $M_{O V}$ implying a negative (stabilising) feedback and negative $M_{O V}$ implying a positive

634 (destabilising) feedback on AMOC changes (Stommel 1961, Rahmstorf 1996). However the

635 relationship between the role of $M_{O V}$ in AMOC bistability (a property of the equilibrium state)

636 and the salinity advection feedback (a transient process) is unclear.

637

638 The role of $M_{O V}$ in AMOC feedbacks and stability was shown by Sijp (2012) to be more

639 complicated than the above advection feedback argument. In the standard argument a

640 negative $M_{O V}$ at a given latitude implies that the $A M O C$ is removing fresh water from the

641 Atlantic basin north of that latitude. A weakening of the AMOC leads to less fresh water

642 removal and hence a fresher Atlantic basin and further AMOC weakening. This feedback

643 focuses on fresh water transport anomalies arising from advection of the mean salinity field

644 by the anomalous flow ( $q^{\prime}<S>$ ); however as noted by Sijp (2012), advection of salinity

645 anomalies by the mean flow $\left(<q>S^{\prime}\right)$ can also be an important term, is stabilising whatever

646 the sign of $M_{O V}$ in the un-hosed state, and can be larger than the first term. A compensation

647 between these two terms can be seen (for $M_{O V}$ at $40^{\circ} \mathrm{N}$ ) in Figure 4c. Further, the gyre/eddy 
648

649

650

651

652

653

654

655

656

657

658

659

660

661

662

663

664

665

666

667

668

669

670

671

672

673

674

675

676

677

678

679

680

681

682

683

684

components of fresh water transport are always down-gradient and are expected to be stabilising. Hence there are both stabilising and destabilising feedbacks, and a stable AMOC is possible even when $M_{O V}<0$, as is believed to be the case in the real present-day ocean.

Given the theoretical importance of and interest in $M_{\mathrm{OV}}$ as a diagnostic of AMOC bi-stability, we ask whether $M_{O V}$ in the un-hosed state contains any information about the distance of the AMOC from the right hand stability threshold, $H_{\text {crit. }}$ This distance does not a priori depend on whether the unperturbed $\mathrm{AMOC}$ is in a mono- or bi-stable régime. Our box model does not contain a physical boundary at $34^{\circ} \mathrm{S}$, so we examine three alternative definitions of the fresh water transport by the AMOC into the Atlantic basin:

$$
N_{O V}=-q\left(S_{T}-S_{N}\right) / S_{0}
$$

is the transport into the $\mathrm{N}$ box (equivalent to the value of $M_{O V}$ at around $40^{\circ} \mathrm{N}$ in FAMOUS, and close to the North Atlantic region used for analysis of the $\mathrm{FAMOUS}_{\mathrm{A}}$ run in J17);

$$
T_{O V}=-q\left[\left(\gamma\left(S_{S}+(1-\gamma) S_{I P}-S_{N}\right] / S_{O}\right.\right.
$$

is the transport into the combined $\mathrm{T}$ and $\mathrm{N}$ boxes (North Atlantic above the NADW layer); and

$$
B_{O V}=-q\left[\left(\gamma\left(S_{S}-S_{B}\right)+(1-\gamma)\left(S_{I P}-S_{B}\right)\right] / S_{O}\right.
$$

is the transport into the combined T, N and B boxes (whole Atlantic plus the global NADW/CDW water mass). $B_{O V}$ is the closest box model equivalent to the conventional ${ }^{34 S} \mathrm{Mov}_{\mathrm{ov}}$, if we assume that the southward transport across $34^{\circ} \mathrm{S}$ is $q S_{B}$. The first term on the right hand side is positive, representing northward fresh water transport by the CWP, and the second term is negative, representing southward transport by the WWP.

The dependence of $H_{c r i t}$ on the un-hosed value of $N_{O V}, T_{O V}$ and $B_{O V}$, for the box model parameter sensitivity experiments described above, is shown in Figure 6b. We see that none of these diagnostics has a clear relationship with $H_{\text {crit }}$ overall. This is unsurprising given the variety of mechanisms by which parameter changes result in changes in $H_{\text {crit, }}$, as discussed in Section 4.1. For example, the sensitivity of $H_{c r i t}$ to $K_{N}$ is a consequence of changes in $N_{O V}$ (see discussion in Section 4.1 and Figure $7 \mathrm{a}$ ), and the 'expected' relationship between $H_{\text {crit }}$ and $N_{O V}$ (i.e. larger $H_{c r i t}$ as $N_{O V}$ increases) is seen in Figure $6 \mathrm{~b}$. On the other hand, the 
685

686

687

688

689

690

691

692

693

694

695

696

697

698

699

700

701

702

703

704

705

706

707

708

709

710

711

712

713

714

715

716

717

718

719

720

721

sensitivity of $H_{c r i t}$ to $K_{I P}$ is primarily due to changes in the salinity of the Indo-Pacific water (Section 4.1), and we see large changes in $H_{c r i t}$ in response to changes in $K_{I P}$, despite only small changes in the un-hosed value of any of $N_{O V}, T_{O V}$ and $B_{O V}$ (Figure $6 b$ ).

Overall we conclude that while the advection of fresh water by the AMOC (quantified by $M_{O V}$ ) plays an important role in the stability of the AMOC, the distance of the unperturbed AMOC from the threshold $\left(H_{\text {crit }}\right)$ is sensitive to a number of processes, so that the unperturbed value of $M_{\mathrm{OV}}$ does not in itself provide a reliable indicator of $H_{\text {crit }}$.

\subsection{Parameter changes at increased $\mathrm{CO}_{2}$ concentration}

Comparing the two FAMOUS $\mathrm{B}_{\mathrm{B}}$ experiments with pre-industrial and doubled $\mathrm{CO}_{2}$, we see that increased $\mathrm{CO}_{2}$ results in an increase in $\mathrm{H}_{\text {crit }}$ by several tenths of a Sverdrup. The different box model parameters for the two states are given in Table 1, and we have performed further box model parameter sensitivity studies changing each of these parameters individually from its $1 \times \mathrm{CO}_{2}$ to its $2 \times \mathrm{CO}_{2}$ value, to determine the main causes of the threshold shift under increased $\mathrm{CO}_{2}$. From these sensitivity studies we find that the dominant factors contributing to the increase in $H_{c r i t}$ are:

a) An increase in the average temperature difference between the North Pacific and the $\mathrm{S}$ box, $T_{\mathcal{S}^{-}} T_{0}$. Causes increase in $H_{\text {crit }}$ of $0.16 \mathrm{SV}$.

b) an increase in the overall strength of the global water cycle, particularly an increase in net Atlantic evaporation $-\left(F_{N}+F_{T}\right)$. Causes increase in $H_{\text {crit }}$ of $0.12 \mathrm{SV}$.

c) changes in the efficiency of the 'gyre' freshwater transports in the Atlantic $\left(K_{S}, K_{N}\right)$. These roughly cancel, leaving an overall increase in $H_{\text {crit }}$ of $0.02 \mathrm{~Sv}$.

The enhanced atmospheric water cycle at increased $\mathrm{CO}_{2}(\mathrm{~b})$ is a robust feature of climate model simulations (Collins et al 2013). The increase in $T_{S}-T_{0}(a)$ is also likely to be a robust result: most of the ocean warming occurs in the upper layers (cf. Gregory 2000, Landerer et al. 2007), so for the same change in heat content the box-mean temperature $T_{S}$ (covering only the top $1000 \mathrm{~m}$ or so of the ocean) changes more than $T_{0}$ (for which a full-depth North Pacific box is used). Changes in gyre transports (c) are less well understood.

To explore whether the increase in $H_{\text {crit }}$ with increasing $\mathrm{CO}_{2}$ is likely to be robust, we have calibrated the box model to the more recent (CMIP5-generation) AOGCM HadGEM2-AO (Martin et al. 2011), in quasi-equilibrium states with $1 \times, 2 \times$, and $4 \times$ pre-industrial $\mathrm{CO}_{2}$, and performed hosing experiments to determine $H_{\text {crit. }}$ Parameter values for these three calibrations are given in Table 1. For HadGEM2-AO we find that $H_{\text {crit }}$ increases by $0.27 \mathrm{~Sv}$ and $0.43 \mathrm{~Sv}$ at $2 \times$, and $4 \times \mathrm{CO}_{2}$ respectively, compared to the $1 \times \mathrm{CO}_{2}$ state (Fig. $5 \mathrm{c}$ ). As was 
seen for FAMOUS $\mathrm{B}_{\mathrm{B}}$, a strengthened fresh water cycle $(\mathrm{b})$ and increased temperature driving

723 (a) both contribute to the increase in $H_{\text {crit }}$; however for the HadGEM2-AO calibrations,

724 increases in $K_{N}$ dominate the changes in the 'gyre' components (c), and make a large contribution to the increase in $H_{\text {crit. }}$. Changes to gyre exchange are less well understood than

726 the other factors above so more uncertainty remains about this contribution. We also see a

727 flattening of the response curve, with a less sharp threshold at higher $\mathrm{CO}_{2}$ in HadGEM2 but

728 not in FAMOUS $_{\mathrm{B}}$. Through single-parameter perturbation experiments (not shown), we find

729 that the flattening is due to the increase of $K_{N}$ at higher $\mathrm{CO}_{2}$, in HadGEM2.

\section{Limits of traceability}

733

734 An advantage of our box modelling approach is that since all the box model state variables

735 and control parameters can be diagnosed directly from GCM solutions (and in principle from

736 observations), the box model provides a low order dynamical framework to analyse the

737 GCM; we can examine discrepancies between the box model and GCM solutions directly,

738 and so understand where the box model breaks down. Indeed we used this process in the

739 development of the box model. For example an earlier, four-box version of the model treated

740 the $\mathrm{N}$ and $\mathrm{B}$ boxes as a single box. While this provided solutions that were qualitatively

741 similar to the GCM, quite large quantitative discrepancies arose, and diagnosis of the

742 discrepancies pointed to the relationship between density and circulation strength (1), which

743 was not as tight as in Figure 2a when the density of the merged $\mathrm{N}$ and $\mathrm{B}$ boxes was used

744 rather than the $\mathrm{N}$ box alone. In this section we examine aspects of the solution where

745 quantitative agreement between box model and GCM solutions remains less good, and

746 diagnose the reasons behind these discrepancies.

\subsection{Atmospheric fresh water feedbacks}

750 As discussed in Section 3 above and in J17, the climate variations associated with AMOC

751 changes through the FAMOUS ${ }_{A}$ hosing experiment result in a slight increase in the surface

752 fresh water flux into the North Atlantic, which accelerates the AMOC weakening. This

753 atmospheric feedback is not included in our box model but by re-running the box model

754 using the time-dependent surface fluxes diagnosed from the $F_{A M O U S_{A}}$ run we assessed

755 that the atmospheric feedback reduces the value of $H_{\text {crit }}$ by about $0.08 \mathrm{SV}$ in FAMOUS $\mathrm{A}_{\mathrm{A}}$. In

756 principle the atmospheric feedback could be parametrised in the box model. However, when

757 we assessed the impact of the feedback in the same way for the FAMOUS $\mathrm{B}_{\mathrm{B}} 2 \mathrm{xCO}_{2}$ run we

758 found that in this case it resulted in an increase in $H_{\text {crit }}$ (again by around $0.08 \mathrm{~Sv}$ ). This 
suggests that the atmospheric feedback on fresh water flux may be noisy and/or difficult to parametrise, so we do not attempt this here but rather consider it an error term in the box model leading to an uncertainty of $\pm 0.08 \mathrm{~Sv}$ in $H_{\text {crit }}$ as estimated by the box model.

\subsection{Left hand threshold}

We note that in Figure 3 the left hand ('ramp down') threshold appears to be less accurately captured than the right hand ('ramp up') threshold. This can be understood as an inherent limitation of the box model, based on the analysis of FAMOUS ${ }_{A}$ by J17. J17 interpreted the $A M O C$ recovery in the ramp-down phase in terms of the North Atlantic salinity budget, as for the ramp up phase. The AMOC-off state and ramp down phase are characterised by a weak reverse overturning circulation $\left(-4 \mathrm{~Sv}\right.$ at $\left.26^{\circ} \mathrm{N}\right)$, and the recovery is driven by advection of salinity anomalies by this circulation. However in the South Atlantic the reverse overturning circulation in the off state is much stronger (-8 Sv, see Figure 3 and J17 Figure 3c). The box model does not differentiate between the AMOC in the North and South Atlantic, and its 'off' state has a strong reverse circulation (-14 Sv) which extends into the North Atlantic boxes, introducing quantitative errors in the salinity advection feedbacks there (note the stronger salinity advection term in the box model than in $\mathrm{FAMOUS}_{\mathrm{A}}$ during the ramp-down phase, green lines in Figure $9 a, b)$. We conclude that the box model is more quantitatively accurate for the 'ramp up' threshold (which is the threshold of most direct interest for future changes), and that the quantitative errors in the 'ramp down' threshold are structural errors that could only be reduced by the addition of extra complexity in the box model (providing meridional structure in the reversed MOC cell).

\subsection{Sensitivity to the method of applying fresh water perturbations}

In our baseline FAMOUS ${ }_{\mathrm{A}}$ hosing hysteresis experiment, as analysed by $\mathrm{H} 11$ and $\mathrm{J} 17$, the hosing is compensated by an opposite surface fresh water extraction over the rest of the ocean surface, to maintain zero global mean fresh water flux (this experiment is called 'SCOMP' in J17). J17 also analyse an alternative FAMOUS ${ }_{\mathrm{A}}$ experiment in which the hosing is compensated by fresh water extraction distributed over the entire ocean volume (designated 'VCOMP'). The VCOMP experiment behaves somewhat differently to SCOMP, showing:

a) a more gradual weakening of the AMOC in VCOMP during the ramp-up phase, although the value of $H_{\text {crit }}$ is similar to SCOMP. J17 attribute this difference to increased near-surface salinities in the subtropical Atlantic in SCOMP (due to the surface hosing compensation) being advected northwards by the MOC ( $\langle q\rangle S^{\prime}$, where 
( ) denotes the unhosed state and a prime denotes departures from it) and so counteracting the freshening effect of the Stommel advection feedback ( $q^{\prime}\left(S^{\prime}\right)$ ). In VCOMP the near-surface freshening is not present, as the compensation is distributed through the water column, so the $\langle q\rangle S^{\prime}$ term is smaller and the AMOC weakens more gradually as $\mathrm{H}$ increases (compare the total fresh water advection by the MOC in FAMOUS ${ }_{A}$, green curves in Figures $4 a(S C O M P)$ and 10a (VCOMP)).

b) The left hand (ramp-down) threshold occurs at a much higher value of $H$ in VCOMP, resulting in a very narrow hysteresis region in the ramp-up/ramp-down experiment, and possibly an almost completely monostable AMOC when more equilibrated solutions are considered (J17 Fig. 2b). This is attributed by J17 to the different South Atlantic reverse cells in the 'off' state in SCOMP and VCOMP.

We have emulated the VCOMP experiment in the box model by distributing the hosing compensation over the whole box model volume. We find only small differences from the box model SCOMP solution in the hysteresis loop and in the detail of the salinity budgets (Figure 10, compare with Figures 3c and 4b). We attribute the lack of impact on the sharpness of the threshold ((a) above) to the limited vertical resolution of the box model: a change in surface flux into the $T$ box in the box model is necessarily spread over a depth of around $1000 \mathrm{~m}$, limiting the surface-intensified $\langle q\rangle S^{\prime}$ feedback which delays AMOC weakening in the FAMOUS. In fact this difference explains why the standard SCOMP box model solution has a more gradual AMOC reduction than seen in FAMOUS (Fig. 3c); in this respect the box model SCOMP solution is intermediate between the FAMOUS SCOMP and VCOMP solutions. This limited vertical resolution is a fundamental structural bias in the box model, when used to emulate SCOMP-type hosing experiments. Turning to the differences (b) between the left-hand thresholds in VCOMP and SCOMP, we have already noted in Section 5.2 that the 'off' state involves changes in the inter-hemispheric structure of the MOC that are not represented by the box model, so it is not surprising that these differences found in $\mathrm{FAMOUS}_{\mathrm{A}}$ by $\mathrm{J} 17$ are not present in the box model ramp-down phase.

\subsection{Discussion of differences between box model and FAMOUS solutions}

Overall we conclude that the box model tends to under-estimate the FAMOUS $H_{\text {crit }}$ by around $0.1-0.2 \mathrm{~Sv}$. Some of this bias is attributable to the lack of feedbacks through atmospheric fresh water fluxes (Section 5.1), and some to the limited vertical resolution of the box model, which reduces a stabilising advection feedback in the SCOMP experiment (Section 5.3). However the box model does include the primary driver of the rapid MOC decline near the ramp-up threshold, namely the quadratic dependence of the salinity advection by the MOC, on the North Atlantic salinity itself. This means that the box model is 
able to pick up the qualitative (and to some extent quantitative) differences in $H_{\text {crit }}$ between different ocean states, and provide a simple framework to understand the main factors determining $H_{\text {crit }}$.

836

837 The box model also produces a more gradual AMOC decline in the ramp-up phase than is seen in the surface-compensated FAMOUS hosing experiments (SCOMP). This reflects the limited vertical resolution of the box model (Section 5.3).

841 By calibrating the box model to different decades in FAMOUS (not shown) and in an ocean

842 reanalysis (Figure $5 \mathrm{~d}$ ), we estimate an additional uncertainty in the right-hand threshold

843 position of at least $\pm 0.04 \mathrm{~Sv}$ due to decadal ocean variability in the calibration variables.

845 The quantitative biases are greater for the left hand (ramp-down) threshold, due to water 846 mass reorganisations in the FAMOUS off state that are not captured by the limited vertical 847 and hemispheric resolution of the box model. However the qualitative similarity between 848 Figures 9 a,b suggests that the box model may still provide useful qualitative insights into 849 the dynamics of the left-hand threshold.

\section{Discussion and conclusions}

852

853 Our results show that the AMOC threshold and hysteresis behaviour in the FAMOUS

854 AOGCM is controlled by low order dynamics, as represented by a 5-box dynamical model.

855 The agreement between the box model and FAMOUS is particularly good for the 'ramp-up'

856 threshold, which is the most relevant for future climate change. The box model parameters

857 are determined by calibration to the baseline (un-hosed) ocean state, implying that the

858 current ocean state contains sufficient information to estimate how far it is from threshold

859 behaviour (e.g. in response to future fresh water input from the Greenland ice sheet).

861 The simplicity of the box model allows us to identify the factors in the ocean state that

862 determine the position of the threshold $H_{\text {crit. }}$. Because the overturning is strongly correlated

863 with the North Atlantic density, we focus here on the salinity budget of the North Atlantic

864 rather than the whole Atlantic basin, following Jackson et al. 2017. As in many previous

865 studies the approach to the threshold is dependent on the 'salinity advection feedback',

866 which involves a quadratic dependence of the AMOC on the North Atlantic salinity (eqn 14).

867 However the exact value of $H_{\text {crit }}$ depends on a balance between the salinity advection

868 feedback and other processes. The un-hosed ('present day') value of $M_{\circ v}$ at either the

869 southern boundary of the Atlantic or in the northern subtropical Atlantic is not in itself a good 
870

871

872

873

874

875

876

877

878

879

880

881

882

883

884

885

886

887

888

889

890

891

892

893

894

895

896

897

898

899

900

901

902

903

904

905

906

predictor of $H_{\text {crit. }}$ Other factors often play more important roles in determining $H_{\text {crit, }}$ including the overall strength of the surface fresh water fluxes (hydrological cycle), the strength of the temperature driving of the flow, and the strength of the 'gyre' (i.e. non-AMOC) exchanges between the different water masses.

In our FAMOUS run with increased $\mathrm{CO}_{2}$ concentrations, $H_{\text {crit }}$ increases by several tenths of a Sverdrup compared to the state with pre-industrial $\mathrm{CO}_{2}$. To the best of our knowledge this is the first time that the AMOC threshold has been evaluated explicitly with increased greenhouse gases. Analysis of the box model calibrated to the FAMOUS runs identifies three main factors driving the increase in $H_{\text {crit, }}$ of which two (surface-intensified ocean warming and a strengthening global water cycle) are likely to be robust features of climate change. The intensified global water cycle means that even though more fresh water is delivered to the deep water formation region, the Atlantic basin as a whole becomes more evaporative $\left(F_{N}+F_{T}\right.$ becomes more negative, Table 1$)$, leading to the increase in $H_{\text {crit. }}$. The same warming and water cycle sensitivities are also seen when the box model is calibrated to a more advanced AOGCM, HadGEM2-AO, with various $\mathrm{CO}_{2}$ concentrations. However, changes in the gyre mixing efficiencies also influence the value of $H_{c r i t}$ at increased $\mathrm{CO}_{2}$, and these changes appear less robust between models, perhaps because they result from changes in the wind field that are model-dependent. Analysis of more AOGCMs would be needed to understand how robust is the increase in $\mathrm{H}_{\text {crit }}$ with increased $\mathrm{CO}_{2}$.

The box model can be calibrated to any AOGCM solution, and therefore opens up the possibility of obtaining a dynamical understanding of the different responses to hosing seen across different AOGCMs (e.g. Rahmstorf et al. 2005, Stouffer et al. 2006, Kageyama et al. 2013). Hysteresis experiments with other AOGCMs will also provide an important test of our model hierarchy, testing the robustness of our conclusions about the dominant AMOC stability mechanisms and allowing the importance of other modelling factors such as Bering Straits throughflow (Hu et al. 2012) or higher resolution (Jungclaus et al. 2013, den Toom et al 2014, Cheng et al. 2018) to be considered. Hysteresis experiments with eddy-resolving coupled models are computationally prohibitive at present but potentially feasible in future; a partial exploration of the hysteresis structure in a current generation (prototype-CMIP6) AOGCM, including an eddy-permitting ocean, has recently been carried out by Jackson and Wood (2018) and will be the subject of future study.

We stress that our study focuses on the response of the AMOC to slowly-varying fresh water forcing. Other processes, beyond those currently included in the box model, may come into play when considering the transient AMOC response to more rapidly varying forcing. 
907 such as transient greenhouse gas increase (e.g. Stocker and Schmittner 1997; Thorpe et al.

908 2001; Gregory et al. 2005; Lucarini and Stone 2005). Such scenarios will be considered in a

909 future study. We note that even the present box model exhibits a range of rate-dependent

910 and duration-dependent responses to rapid changes in fresh water forcing (Alkhayuon et al.

911 2019).

912

913 While uncertainty remains over the quantitative modelling of changes in the AMOC threshold

914 under increased greenhouse gases, our model hierarchy approach has identified some

915 simple, low order dynamical controls on the threshold that can in principle be determined

916 from observations (directly or through data-assimilating reanalyses). These observations

917 provide a dynamically-based 'emergent constraint' (Hall and Qu 2006; Cox et al. 2018) on

918 the position of the threshold. Hence it may be possible to monitor whether the threshold is

919 becoming closer or further away, using large-scale oceanographic observations, to provide

920 early warning of any approaching regime shift. This is particularly important because, as with

921 many AOGCMs, FAMOUS and HadGEM2-AO overestimate the northward freshwater flux

$922 M_{O V}$ carried across $34^{\circ} \mathrm{S}$ by the AMOC (Huisman et al. 2010; H11; Rodríguez et al. 2011;

923 Mecking et al. 2017). While we showed in Section 4.3 that $M_{O V}$ is not a direct indicator of

$924 H_{\text {crit, }}$ this bias suggests that the salinity advection feedback may excessively stabilise the

925 AMOC in our AOGCMs (Drijfhout et al. 2011; Cimatoribus et al. 2012; Jackson 2013). So,

926 even if it were possible to perform hosing runs with all current AOGCMs, relying on the

927 current ensemble of AOGCMs to estimate $H_{\text {crit }}$ may give a biased result. To obtain a

928 preliminary estimate of $H_{\text {crit, }}$, based on observations we have calibrated the box model to

929 ocean states derived from an ocean reanalysis (Smith et al. 2007), which has Mov around -

$9300.2 \mathrm{~Sv}$, close to observational estimates (H11) (Figure 5d). This yields an AMOC threshold

931 at about $0.35 \mathrm{SV}$, suggesting that the GCMs studied here $\left(\right.$ FAMOUS $_{\mathrm{A}}, \mathrm{FAMOUS}_{\mathrm{B}}$ and

932 HadGEM2-AO) may all be slightly further from an AMOC threshold than the real ocean.

933 Calibration of the box model to a wider range of both AOGCMs and ocean analyses, and a

934 thorough uncertainty analysis of the observational constraints, are needed to provide a

935 robust result; this will be the subject of a future study.

936

937 


\section{References:}

Alkhayuon, H., P. Ashwin, L.C. Jackson, C. Quinn and R.A. Wood, 2019: Basin bifurcations, oscillatory instability and rate-induced thresholds for Atlantic meridional overturning circulation in a global oceanic box model. Proc. R. Soc. A, 475: 20190051, http:dx.doi.org/10.1098/rspa.2019.0051

Alley, R.B., 2003: Palaeoclimatic insights into future climate challenges. Phil. Trans. Roy Soc. A, 361, 1831-1848.

Bakker, P., A. Schmittner, J.T.M. Lenaerts, A. Abe-Ouchi, D. Bi, M.R.van den Broeke, W.L. Chan, A. Hu, R.L. Beadling, S.J. Marsland, S.H. Mernild, O.A. Saenko, D. Swingedouw, A. Sullivan and J. Yin, 2016: Fate of Atlantic Meridional Overturning Circulation: Strong decline under continued warming and Greenland melting. Geophys. Res. Lett., 43, 12252-12260, doi:10.1002/2016GL070457.

Bryden, H. L. \& S. Imawaki 2001 Ocean heat transport, in Ocean Circulation and Climate, edited by G. Siedler, J. Church \& J. Gould, Academic Press, pp 455-474.

Cheng, w., W. Weijer, W.M. Kim, G. Danabasoglu, S.G. Yeager, P.R. Gent, D. Zhang, J.C.H. Chang and J. Zhang, 2018: $\mathrm{Cn}$ the salt advection feedback be detected in internal variability of the Atlantic Meridional Overturning Circulation? J. Climate, 31, 6649-6667, doi: 10.1175/JCLI-D-17-0825.1

Cimatoribus, A.A., S.S. Drijfhout, M. den Toom and H.A. Dijkstra, 2012: Sensitivity of the Atlantic meridional overturning circulation to South Atlantic freshwater anomalies. Climate Dyn., 39, 2291-2306, doi: 10.1007/s00382-012-1292-5.

Collins, M., R. Knutti, J. Arblaster, J.-L. Dufresne, T. Fichefet, P. Friedlingstein, X. Gao, W.J. Gutowski, T. Johns, G. Krinner, M. Shongwe, C. Tebaldi, A.J. Weaver and M. Wehner, 2013: Long-term Climate Change: Projections, Commitments and Irreversibility. In: Climate Change 2013: The Physical Science Basis. Contribution of Working Group I to the Fifth Assessment Report of the Intergovernmental Panel on Climate Change [Stocker, T.F., D. Qin, G.-K. Plattner, M. Tignor, S.K. Allen, J. Boschung, A. Nauels, Y. Xia, V. Bex and P.M. Midgley (eds.)]. Cambridge University Press, Cambridge, United Kingdom and New York, NY, USA.

Cox, P.M., C. Huntingford and M.S. Williamson, 2018: Emergent constraint on equilibrium climate sensitivity from global temperature variability. Nature, 553, 319-322.

Den Toom, M., H.A. Dijkstra, W.Weijer, M.W. Hecht, M.E. Maltrud and E. Van Sebile, 2014: Response of a Strongly Eddying Global Ocean to North Atlantic Freshwater Perturbations. J. Phys. Ocenaogr.,44, 464-481, DOI:10.1175/JPO-D-12-0155.1

deVries, P. and S.L. Weber, 2005: The Atlantic fresh water budget as a diagnostic for the existence of a stable shut down of the meridional overturning circulation. Geophys. Res. Lett., 32, doi:10.1029/2004GL021450.

Dijkstra, H. A., 2007, Characterization of the multiple equilibria regime in a global ocean model. Tellus A, 59, 695-705, DOI: 10.1111/j.1600-0870.2007.00267.x

Dijkstra, H.A. and Neelin, J.D., 1999: Imperfections of the thermohaline circulation: multiple equilibria and flux correction. J. Climate, 12, 1382-1392.

Dijkstra, H.A., L. Te Raa and W. Weijer (2004): A systematic approach to determine thresholds of the ocean's thermohaline circulation. Tellus $A, 56,362-370$, doi:10.1111/j.1600-0870.00058.x

Döös, K., 1995: Interocean exchange of water masses. J. Geophys. Res., 100, 13499-13514.

Drijfhout, S.S., Weber, S.L. and van der Swaluw, E., 2011: The stability of the MOC as diagnosed from model projections for pre-industrial, present and future climates. Climate Dyn., 37, 1575-1586. 
Fichefet, T, C. Poncin, H. Goosse, P. Huybrechts, I. Janssens and H. Le Treut, 2003: Implications of changes in freshwater flux from the Greenland ice sheet for the climate of the 21st century. Geophys. Res. Lett., 30, doi:10.1029/2003GL017826.

Gnanadesikan, A., 1999: A simple predictive model for the structure of the oceanic pycnocline. Science, 283, 2077-2079.

Gordon,C., C. Cooper, C.A. Senior, H.T. Banks, J.M. Gregory, T.C. Johns, J.F.B. Mitchell and R.A. Wood, 2000: The simulation of SST, sea ice extents and ocean heat transports in a version of the Hadley Centre coupled model without flux adjustments. Climate Dyn., 16, 147-168.

Gregory, J.M., 2000: Vertical heat transports in the ocean and their effect on time-dependent climate change. Climate Dyn., 16, 501-515.

Gregory, J.M., O.A. Saenko and A.J. Weaver, 2003: The role of the Atlantic freshwater balance in the hysteresis of the meridional overturning circulation. Climate Dyn., 21, 707-717

Gregory, J.M. et al. 2005: A model intercomparison of changes in the thermohaline circulation in response to increasing atmospheric $\mathrm{CO}_{2}$ concentration. Geophys. Res. Lett., 32, doi:10.1029/2005GL023209.

Hall, A. and X. Qu, 2006: Using the current seasonal cycle to constrain snow albedo feedback in future climate change. Geophys. Res. Lett. 33, L03502

Hawkins, E., R. S. Smith, L. C. Allison, J. M. Gregory, T. J. Woollings, H. Pohlmann, and B. de Cuevas, 2011: Bistability of the Atlantic overturning circulation in a global climate model and links to ocean freshwater transport, Geophys. Res. Lett., 38, L10605, doi:10.1029/2011GL047208.

Hofmann, M. and S. Rahmstorf, 2009: On the stability of the Atlantic meridional overturning circulation. Proc. Natl. Acad. Sci., doi: 10.1073/pnas.0909146106

Hu, A. G.A. Meehl, W. Han, A. Abe-Ouchi, C. Morrill, Y. Ozaki and M.O. Chikamoto, 2012: The Pacific-Atlantic seesaw and the Bering Strait. Geophys. Res. Lett. 39, L03702, doi: 10.1029/2011GL050567.

Hughes, T.M.C and A.J. Weaver, 1994: Multiple equilibria of an asymmetric 2-basin ocean model. J. Phys. Oceanogr., 24, 619-637.

Huisman, S. E., M. Den Toom, H. A. Dijkstra and S. Drijfhout, 2010: An indicator of the multiple equilibria regime of the Atlantic meridional overturning circulation. J. Phys'. Oceanogr., 40, 551-567. doi: 10.1175/2009JPO4215.1

Jackson, L.C., 2013: Shutdown and recovery of the AMOC in a coupled global climate model: The role of the advective feedback. Geophys. Res. Lett., 40, 1182-1188, doi: 10.1002/grl.50289

Jackson, L., R.Kahana, T. Graham, M.A. Ringer, T. Woolings, J.V. Mecking and R.A. Wood, 2015: Global and European climate impacts of a slowdown of the AMOC in a high resolution GCM. Clim. Dyn., 45, 3299-3316, doi: 10.1007/s00382-015-2540-2.

Jackson, L.C., R.S. Smith and R.A. Wood, 2017: Ocean and atmosphere feedbacks affecting AMOC hysteresis in a GCM. Climate Dyn., doi: 10.1007/s00382-016-3336-9

Jackson, L.C. and R.A. Wood, 2018: Hysteresis and resilience of the AMOC in an eddy-permitting GCM. Geophys. Res. Lett., doi: 10.1029/2018GL078104.

Johnson, H.L., D.P. Marshall and D.A.J. Sproson, 2007: Reconciling theories of a mechanically driven meridional overturning circulation with thermohaline forcing and multiple equilibria. Climate Dyn., 29, 821-836, doi: 10.1007/s00382-007-026249.

Jungclaus, J.H., N. Fischer, H. Haak, K. Lohmann, J. Marotzke, D. Matei, U. Mikolajewicz, D. Notz, J. S. von Storch, 2013: Characteristics of the ocean simulations in the Max Planck Institute Ocean 
Model (MPIOM) the ocean component of the MPI-Earth system model. J. Adv. in Modelling Earth Systems, 5, 422-446

Kageyama, M., U. Merkel, B. Otto-Bliesner, M. Prange, A. Abe-Ouchi, G. Lohmann, R. Ohgaito, D. M. Roche, J. Singarayer, D. Swingedouw, and X Zhang, 2013: Climatic impacts of fresh water hosing under Last Glacial Maximum conditions: a multi-model study. Clim. Past, 9, 935-953, doi:10.5194/cp9-935-2013

Landerer, F.W., J.H. Jungclaus and J. Marotzke, 2007: Regional dynamic and steric sea level change in response to the IPCC-A1B scenario. J. Phys. Oceanogr., 37, 296-312.

Lenton, T.M. et al., 2007: Effects of atmospheric dynamics and ocean resolution on bi-stability of the thermohaline circulation examined using the Grid ENabled Integrated Earth system modelling (GENIE) framework. Climate Dyn., 29, 591-613.

Liu, W., S. Xie, Z. Liu and J. Zhu, 2017: Overlooked possibility of a collapsed Atlantic Meridional Overturning Circulation in warming climate. Sci. Adv., 3, e1601666,

Lucarini, V. and P.H.Stone, 2005: Thermohaline circulation stability: a box model study. Part I: uncoupled model. J. Phys. Oceanogr., 18, 501-513.

Manabe, S. and Stouffer, R.J., 1988: Two stable equilibria of a coupled ocean-atmosphere model. J. Climate, 1, 841-863.

Marotzke, J. and Stone, P.H., 1995: Atmospheric transports, the thermohaline circulation, and flux adjustments in a simple coupled model. J. Phys. Oceanogr., 25, 1350-1364.

Martin, G.M. et al., 2011: The HadGEM2 family of Met Office Unified Model climate configurations. Geosci. Model Dev., 4, 723-757.

Mecking, J.V., S.S.Drijfhout, L.C. Jackson and M.B.Andrews, 2017: Theeffect of model bias on Atlantic freshwater transport and implications for AMOC bi-stability. Tellus A, 69:1, doi:10.1080/16000870.2017.1299910.

Mikolajewicz, U. et al., 2007: Long-term effects of anthropogenic CO2 emissions simulated with a complex earth system model. Climate Dyn., 6, 599-631.

Muglia, J., L.C. Skinner and A. Schmittner,2018: Weak overturning circulation and high Southern Ocean nutrient utilization maximised glacial ocean carbon. Earth plan. Sci. Lett., 496, 47-56, doi:10.1016/j.epsl.2018.05.038

Pardaens, A.K., Banks, H.T., Gregory, J.M. and Rowntree, P.R., 2003: Freshwater transports in HadCM3. Clim. Dyn., 21, 177-195.

Pfeffer, W.T., Harper, J.T. and O'Neel, S., 2008: Kinematic constraints on glacier contributions to 21st-cnetury sea-level rise. Science, 321, 1340-1343.

Rahmstorf, S., 1996: On the Freshwater Forcing and Transport of the Atlantic Thermohaline Circulation, Climate Dyn., 12, 799-811, DOI: 10.1007/s003820050144

Rahmstorf, S. et al., 2005: Thermohaline circulation hysteresis: A model intercomparison. Geophys. Res. Lett., 32, L23605, doi:10.1029/2005GL023655

Rodríguez, J.A., T.C. Johns, R.B. Thorpe and A. Wiltshire, 2011: Using moisture conservation to evaluate oceanic surface freshwater fluxes in climate models. Climate Dyn., 37, 205-219.

Schneider, S.H., S. Semenov, A. Patwardhan, I. Burton, C.H.D. Magadza, M. Oppenheimer, A.BV. Pittock, A. Rahman, J.B. Smith, A. Suarez and F. Yamin, 2007: Assessing key vulnerabilities and the risk from climate change. In Climate Change 2007: Impacts, adaptation and vulnerability. Contribution of Working Group II to the Fourth Assessment Report of the Intergovernmental Panel on Climate 
Change, M.L. Parry, O.F. Canziani, J.P. palutikof, P.J. van der Linden and C.E. Hansen, eds., Cambridge University Press, Cambridge, UK, 779-810.

Sijp, W.P., 2012: Characterising meridional overturning bistability using a minimal set of state

Smith, D. M. et al.,2007: Improved surface temperature prediction for the coming decade from a global climate model, Science, 317, 796-799.

Smith, R.S., 2012: The FAMOUS climate model (versions XFXWB and XFHCC): description and update to version XDBUA. Geosci. Model Dev., 5, 269-276.

Smith, R.S. and Gregory, J.M., 2009: A study of the sensitivity of ocean overturning circulation and climate to freshwater input in different regions of the North Atlantic. Geophys. Res. Lett., 36, doi:10.1029/2009GL038607.

Smith, R.S., J.M. Gregory and A. Osprey, 2008:A description of the FAMOUS (version XDBUA) climate model and control run. Geosci. Model Dev., 1, 53-68.

Speich, S., B. Blanke and G. Madec, 2001:Warm and cold water routes of an O.G.C.M. thermohaline conveyor belt. Geophys. Res. Lett., 28,311-314.

Stocker, T.F. and A. Schmittner, 1997: Influence of $\mathrm{CO}_{2}$ emission rates on the stability of the thermohaline circulation. Nature, 388, 862-864.

Stommel, H. (1961). Thermohaline convection with two stable regimes of flow. Tellus, 13, 224-230.

Stouffer, R.J., K. W. Dixon, M. J. Spelman, W. Hurlin, J. Yin, J. M. Gregory, A. J. Weaver, M. Eby, G. M. Flato, D. Y. Robitaille, H. Hasumi, A. Oka, A. Hu, J. H. Jungclaus, I. V. Kamenkovich, A. Levermann, S. Nawrath, M. Montoya, S. Murakami, W. R. Peltier, G. Vettoretti, A. Sokolov, and S. L. Weber, 2006: Investigating the causes of the response of the thermohaline circulation to past and future climate changes. Journal of Climate, 19(8):1365-1387.

Swingedouw, D., C.B. Rodehacke, S.M. Olsen, M. Menary, Y. Gao, U. Mikolajewicz and J. Mignot, 2015: On the reduced sensitivity of the Atlantic overturning to Greenland ice sheet melting in projections: a multi-model assessment. Clim. Dyn., 44, 3261-3279, doi: 10.1007/s00382-014-2270-x.

Talley, L.D., G.L. Pickard, W.J. Emery and J.H. Swift, 2011: Descriptive Physical Oceanography: An Introduction. Sixth Edition. Academic Press, Oxford, UK, 555 pp.

Thorpe, R., J.M. Gregory, T.C. Johns, R.A. Wood and J.F.B. Mitchell, 2001: Mechanisms determining the Atlantic thermohaline circulation response to greenhouse gas forcing in a non-flux-adjusted coupled climate model. J. Climate, 14, 3102-3116.

Valdes, P., 2011: Built for stability? Nature Geosci., 4, 414-416.

Vellinga, M. \& Wood, R.A., 2002: Global climate impacts of a collapse of the Atlantic thermohaline circulation. Climatic Change, 54, 251-267.

Vellinga, M., R.A. Wood \& J.M. Gregory, 2002: Coupled ocean-atmosphere feedbacks governing the recovery of a perturbed thermohaline circulation. J. Climate, 15, 764-780.

Weber, S.L., S.S. Drijfhout, A. Abe-Ouchi, M. Crucifix, M. Eby, A. Ganopolski, S. Murakami, B. OttoBliesner and W.R. Peltier, 2007: The modern and glacial overturning circulation in the Atlantic Ocean in PMIP coupled model simulations. Clim. Past, 3, 51-64. 
1173

\begin{tabular}{|c|c|c|c|c|c|c|c|}
\hline Parameter & $\begin{array}{l}\text { FAMOUS }_{A} \\
1 \times \mathrm{CO}_{2}\end{array}$ & $\begin{array}{l}\text { FAMOUS }_{B} \\
1 \times \mathrm{CO}_{2}\end{array}$ & $\begin{array}{l}\text { FAMOUS }_{B} \\
2 \times \mathrm{CO}_{2}\end{array}$ & $\begin{array}{l}\text { HadGEM2- } \\
\mathrm{AO} \\
1 \times \mathrm{CO}_{2}\end{array}$ & $\begin{array}{l}\text { HadGEM2- } \\
\mathrm{AO} \\
2 \times \mathrm{CO}_{2}\end{array}$ & $\begin{array}{l}\text { HadGEM2- } \\
\mathrm{AO} \\
4 \times \mathrm{CO}_{2}\end{array}$ & $\begin{array}{l}\text { DePreSys } \\
1999-2008\end{array}$ \\
\hline$V_{N}\left(\mathrm{~m}^{3} \times 10^{16}\right)$ & 3.683 & 3.261 & 3.683 & 3.557 & 5.259 & 5.257 & 4.854 \\
\hline$V_{T}\left(m^{3} \times 10^{16}\right)$ & 5.151 & 7.777 & 5.418 & 8.908 & 7.400 & 7.454 & 7.583 \\
\hline$V_{s}\left(\mathrm{~m}^{3} \times 10^{16}\right)$ & 10.28 & 8.897 & 6.097 & 10.330 & 9.336 & 9.462 & 17.247 \\
\hline$V_{I P}\left(\mathrm{~m}^{3} \times 10^{16}\right)$ & 21.29 & 22.02 & 14.86 & 19.219 & 19.220 & 19.155 & 38.856 \\
\hline$V_{B}\left(\mathrm{~m}^{3} \times 10^{16}\right)$ & 88.12 & 86.490 & 99.25 & 90.23 & 89.90 & 90.78 & 73.55 \\
\hline$A_{N}$ & 0.194 & 0.070 & 0.131 & 0.117 & 0.285 & 0.197 & 0.194 \\
\hline $\boldsymbol{A}_{T}$ & 0.597 & 0.752 & 0.696 & 0.703 & 0.522 & 0.620 & 0.608 \\
\hline$A_{s}$ & -0.226 & -0.257 & -0.263 & -0.303 & -0.299 & -0.326 & -0.282 \\
\hline$A_{I P}$ & -0.565 & -0.565 & -0.564 & -0.517 & -0.508 & -0.491 & -0.519 \\
\hline$F_{N}(\mathrm{~Sv})$ & 0.375 & 0.384 & 0.486 & 0.453 & 0.496 & 0.577 & 0.531 \\
\hline$F_{S}(S v)$ & 1.014 & 1.078 & 1.265 & 0.901 & 1.021 & 1.114 & 0.849 \\
\hline$F_{T}(\mathrm{~Sv})$ & -0.723 & -0.723 & -0.997 & -0.798 & -0.921 & -1.099 & -0.743 \\
\hline$F_{I P}(\mathrm{~Sv})$ & -0.666 & -0.739 & -0.754 & -0.556 & -0.596 & -0.592 & -0.637 \\
\hline$T_{S}\left({ }^{\circ} \mathrm{C}\right)$ & 5.571 & 4.773 & 7.919 & 6.456 & 7.424 & 8.710 & 4.385 \\
\hline$T_{0}\left({ }^{\circ} \mathrm{C}\right)$ & 3.26 & 2.65 & 3.87 & 2.71 & 3.29 & 3.70 & 2.12 \\
\hline $\begin{array}{l}\mu\left({ }^{\circ} \mathrm{Cm}^{-3} \mathrm{~s}\right. \\
\left.\times 10^{-8}\right)\end{array}$ & 7.0 & 5.5 & 22.0 & 1.4 & 16.0 & 28.0 & 2.7 \\
\hline $\begin{array}{l}\lambda\left(m^{6} \mathrm{~kg}^{-1} \mathrm{~s}^{-1}\right. \\
\left.\mathrm{x} 10^{7}\right)\end{array}$ & 2.66 & 2.79 & 1.62 & 2.17 & 1.66 & 1.28 & 3.53 \\
\hline$K_{N}(\mathrm{~Sv})$ & 5.439 & 5.456 & 1.762 & 5.601 & 15.890 & 20.954 & 17.07 \\
\hline$K_{S}$ (Sv) & 1.880 & 5.447 & 1.872 & 7.169 & 6.828 & 8.384 & 3.546 \\
\hline$K_{I P}(\mathbf{S v})$ & 89.778 & 96.817 & 99.977 & 459.095 & 1029.641 & 477.332 & 192.649 \\
\hline$\eta(\mathrm{Sv})$ & 66.061 & 74.492 & 33.264 & 3.758 & 9.871 & 6.773 & 19.689 \\
\hline$y$ & 0.58 & 0.39 & 0.36 & 0.85 & 0.73 & 0.39 & 0.33 \\
\hline
\end{tabular}

1174

1175

1176

1177 Box model parameter values for all calibrations used in this paper. The parameters $A_{N}, A_{T}$,

$1178 A_{S}$ and $A_{I P}$ are multiplicative factors for the hosing for their respective boxes and depend on

1179 the latitudes of the box boundaries. In the AOGCM the hosing is added to the region 20-

$118050^{\circ} \mathrm{N}$ of the Atlantic, with a compensating fresh water removal from the rest of the global

1181 ocean surface. Typically the AOGCM hosing region spans some of the $\mathrm{N}$ box and some of

1182 the $\mathrm{T}$ box. The $A$ 's are chosen to give the same total fresh water flux $H . A_{i}$ into each box as

1183 in the corresponding AOGCM run $\left(A_{N}+A_{T}+A_{S}+A_{I P}=0\right)$. 
1186 a.

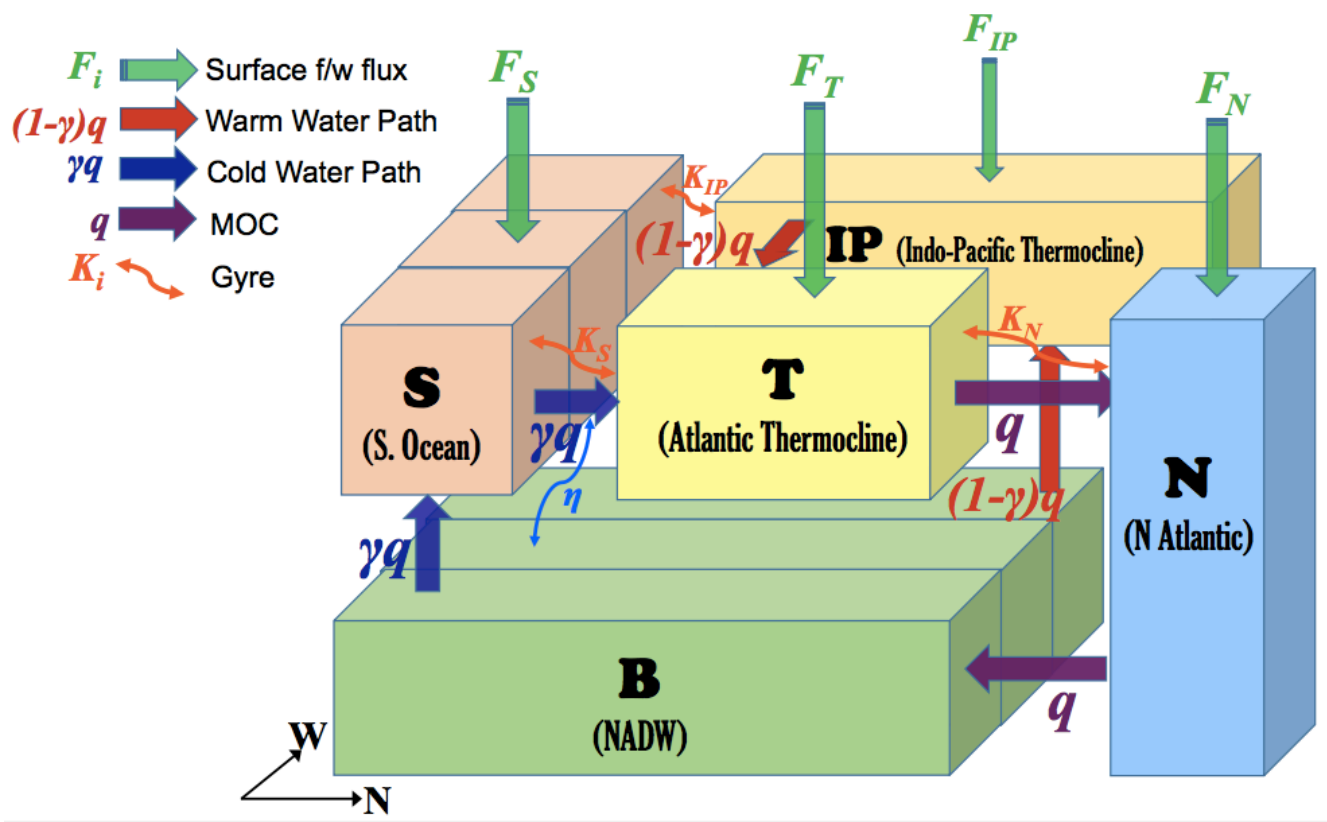

\section{8 b.}

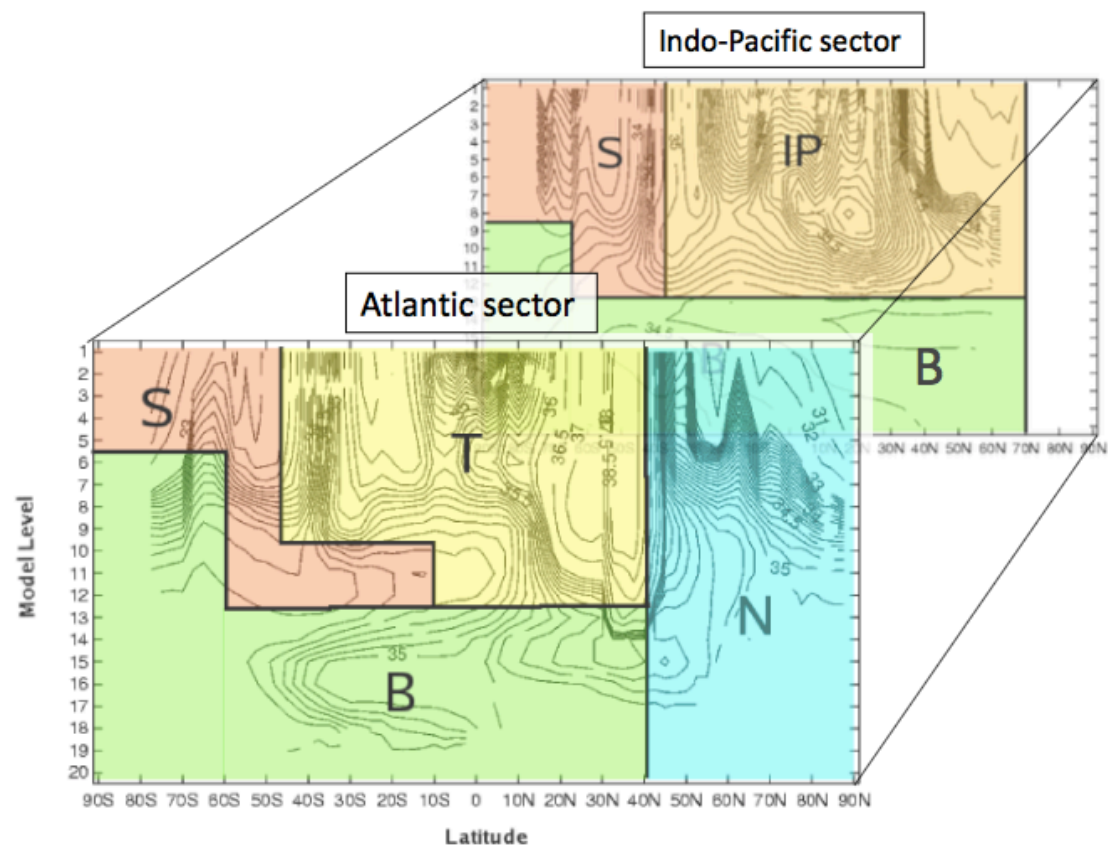

1190 Fig. 1 Box model definition

1191 (a) Schematic representation of the box model. The control parameters of the model are the 1192 temperature difference between $\mathrm{N}$ and $\mathrm{S}$ boxes, the pipe constant $(\lambda)$, the surface 
1193 freshwater fluxes $\left(\mathrm{F}_{\mathrm{i}}\right)$, the wind-driven transport constants $\left(\mathrm{K}_{\mathrm{i}}\right)$, the $\mathrm{S}-\mathrm{B}$ box mixing parameter

1194 ( $\eta$ ) and the proportion of the cold water path $(\mathrm{\gamma})$. All parameters except $\mathrm{Y}$ can be diagnosed

1195 from any GCM state, or in principle from observations. (b): Boundaries of model boxes used

1196 in the calibration of the box model to the FAMOUS $\mathrm{A}$ pre-industrial $\left(1 \mathrm{xCO}_{2}\right)$ run,

1197 superimposed on the zonal average of the FAMOUS ${ }_{A}$ salinity distribution across the Atlantic 1198 and Indo-Pacific Oceans

1199 
a.

1201

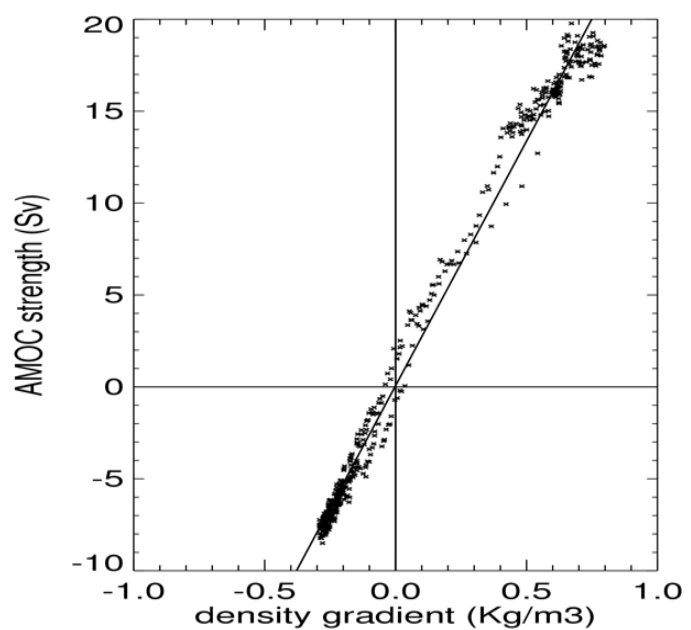

1202 b.

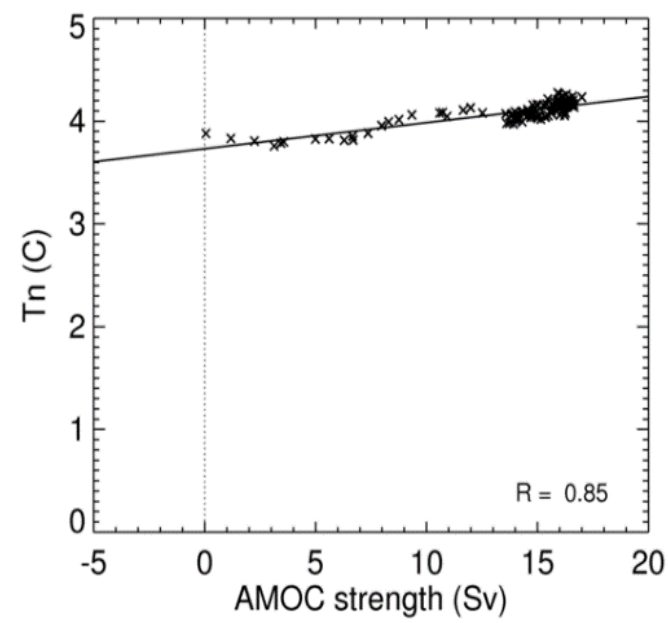

1203

1204 Fig. 2

1205 (a) AMOC strength as function of N-S density difference. Scatter plot of FAMOUS $_{A}$ AMOC

1206 strength vs. density difference between the two portions of the ocean that define the $\mathrm{N}$ and S

1207 boxes in the box model. The points shown cover the entire hysteresis run with preindustrial $1208 \mathrm{CO}_{2}$

1209 (b) Temperature of $\mathrm{N}$ box as a function of AMOC strength. Scatter plot of $\mathrm{FAMOUS}_{\mathrm{A}}$ box1210 mean temperature $T_{N}$ vs. AMOC strength $q$. The points shown cover the part of hysteresis 1211 between the unhosed state and the first threshold crossing, for the run with preindustrial $1212 \mathrm{CO}_{2}$. 
a.

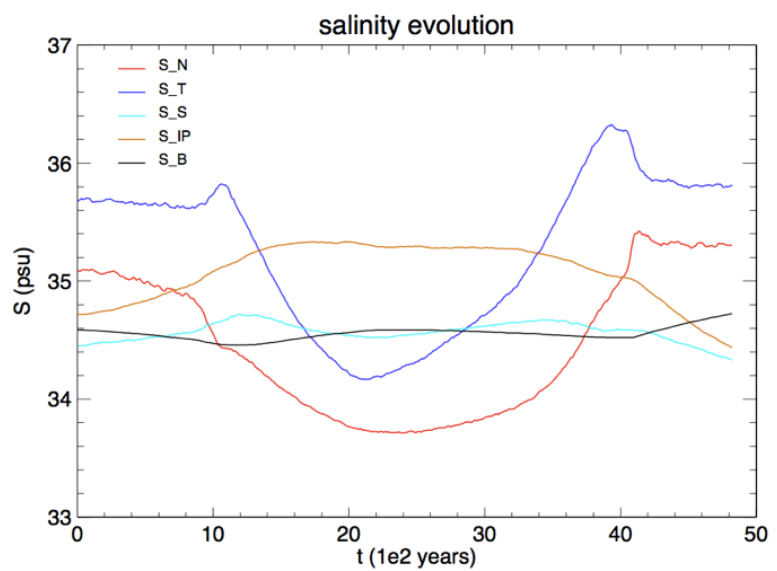

1215 b

1216

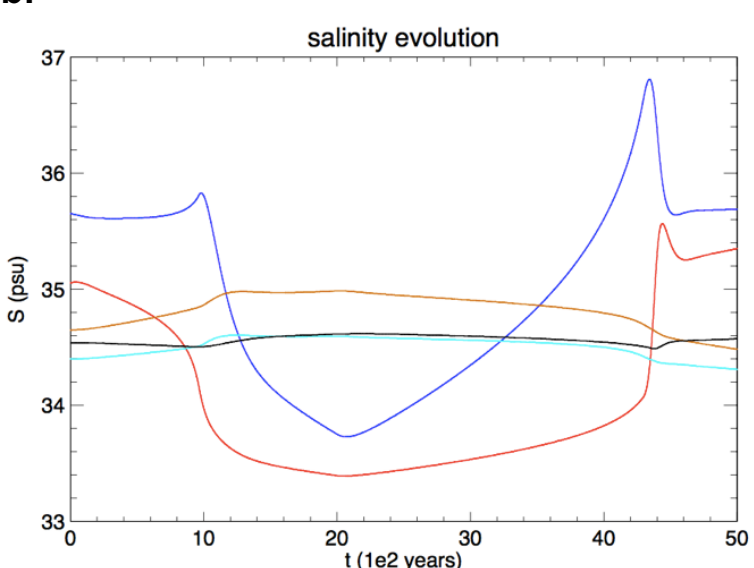

1217

c.

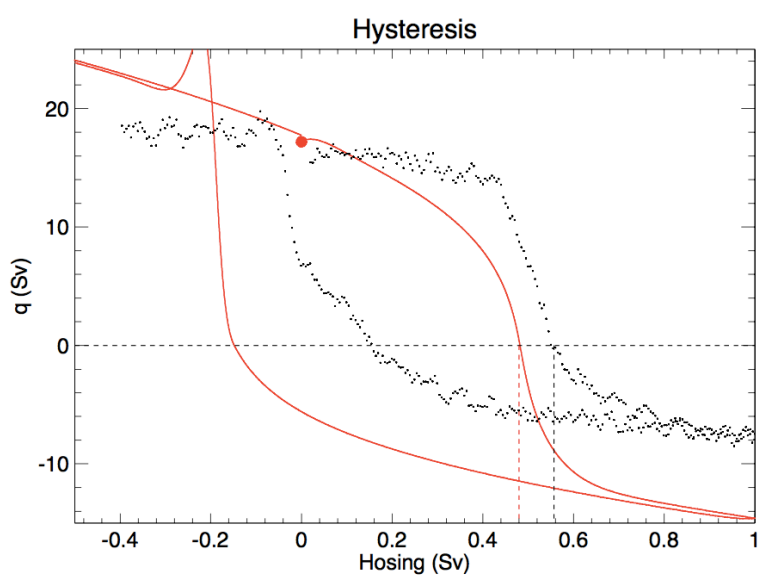

1219 Fig. 3: Comparison between FAMOUS A $_{\mathrm{A}}$ and box model simulations

1220 (a) Salinity evolution in the five model boxes through the 5000 years of the FAMOUS $_{A}$ hosing 1221 experiment [H11] (b) As (a) but for the corresponding box model experiment. The same rate 1222 of increase of hosing is used for both experiments. (c) AMOC strength as function of hosing

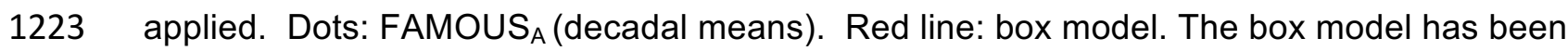


1224 calibrated solely to the unperturbed initial state of FAMOUS $_{A}$ (shown by the red dot). The 1225 dashed lines show the critical hosing value $H_{\text {crit. }}$ 
a.

1227

1228

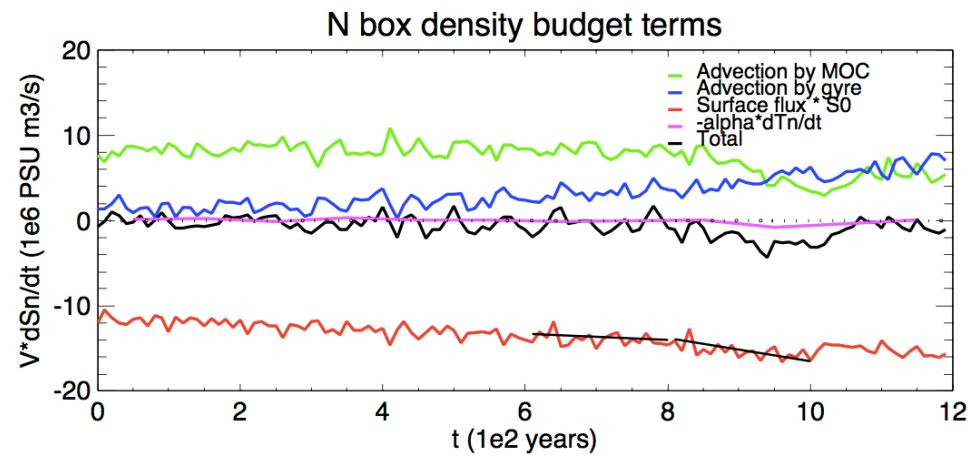

b.

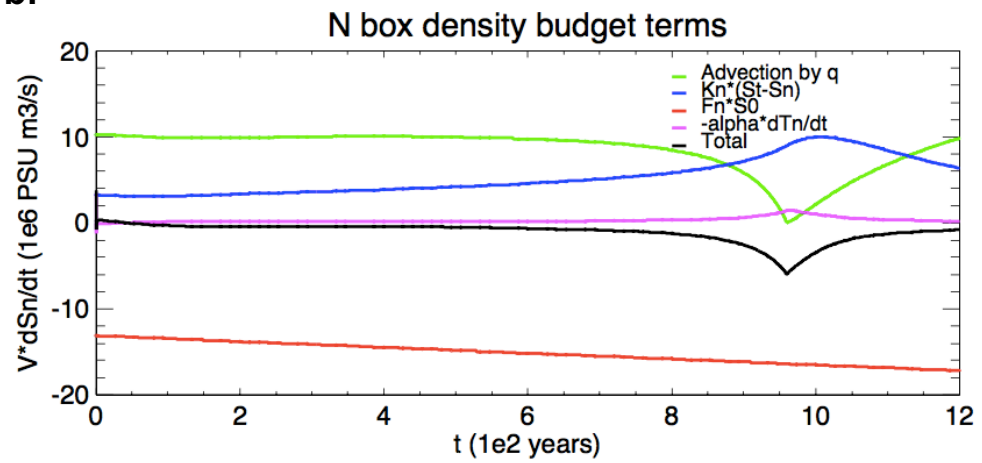

1229

1230

c.

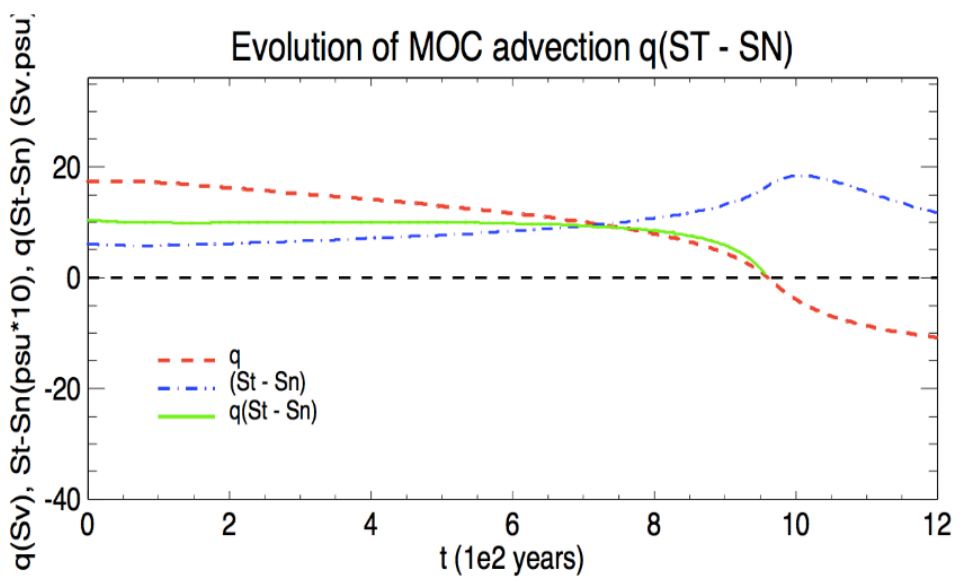

1231

1232

1233

Fig. 4

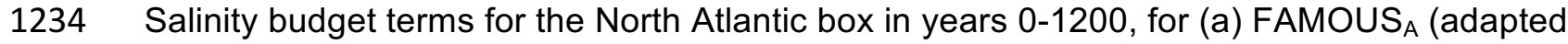
1235 from J17), (b) box model. Black: $\mathrm{dS}_{\mathrm{N}} / \mathrm{dt}$; red: surface flux (including hosing); green; advection 1236 by MOC; blue: advection by gyre(FAMOUS)/diffusion by $\mathrm{K}_{\mathrm{N}}$ (box model). Also shown is the 1237 density change due to temperature response to the AMOC, converted into an equivalent 1238 salinity change (pink). Average slope lines for years 601-800 and 801-1000 are shown for the surface flux term in (a) to illustrate the atmospheric water flux feedback. The individual components of the fresh water transport by the MOC, $-q\left(S_{T}-S_{N}\right)$, are shown for the box model in (c) [Red: $q(\mathrm{~Sv})$; blue: $\left(S_{T}-S_{N}\right)(p s u * 10)$; Green: $-q\left(S_{T}-S_{N}\right)(S v . p s u)$. 
a.

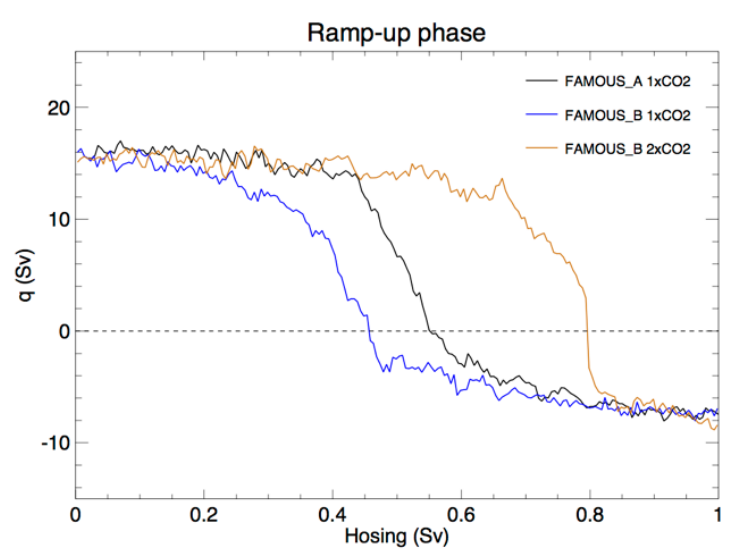

1244

1245

c.

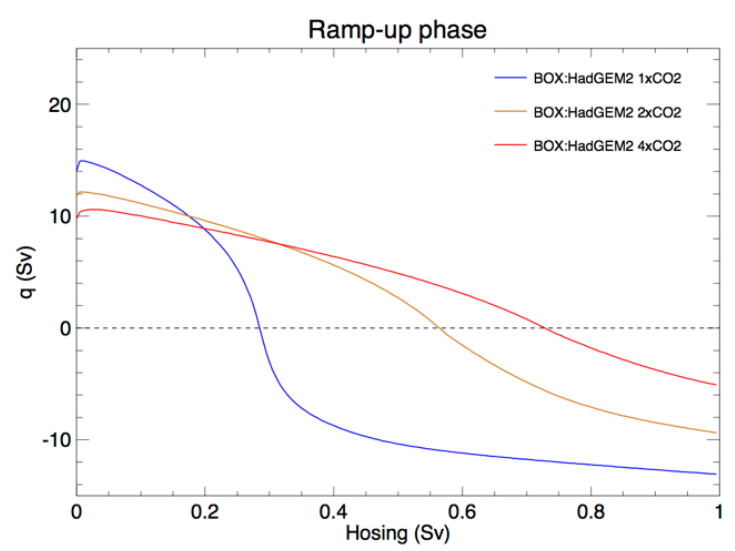

b.

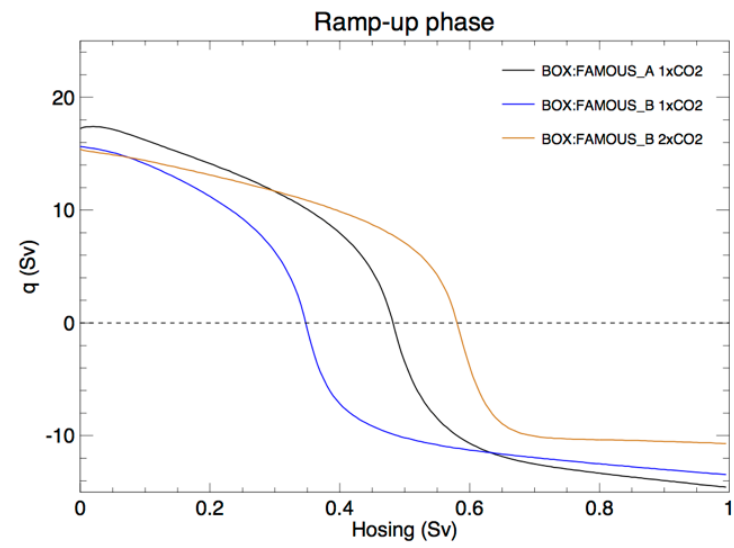

d.

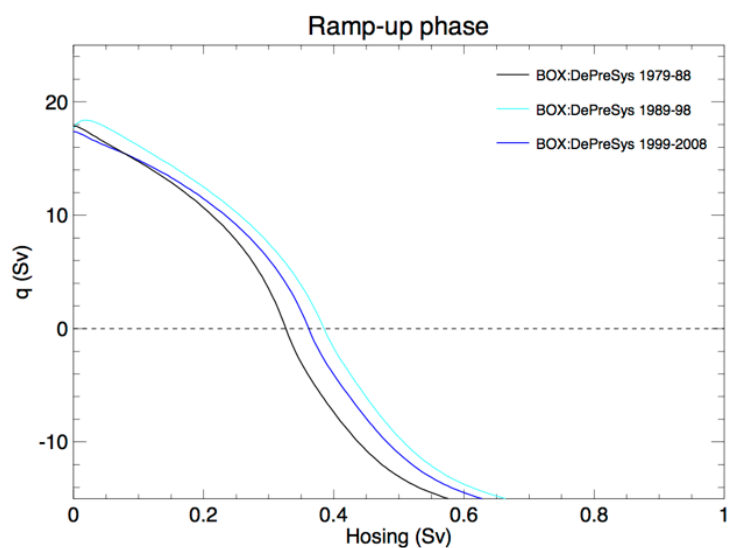

1248 Fig. 5 AMOC thresholds in preindustrial and increased $\mathrm{CO}_{2}$ simulations

1249 AMOC strength as function of hosing applied in transient experiments from various near-

1250 equilibrated $\mathrm{CO}_{2}$ states. Only the 'ramp-up' part of the experiment (hosing increasing up to $12511.0 \mathrm{~Sv}$ ) is shown. (a) FAMOUS $\mathrm{A}_{\mathrm{A}}$ at pre-industrial $\mathrm{CO}_{2}$ (black), FAMOUS $\mathrm{B}_{\mathrm{B}}$ at pre-industrial 1252 (blue) and $2 \times \mathrm{CO}_{2}$ (brown); (b) box model calibrated to the three FAMOUS runs shown in 1253 (a); (c) box model calibrated to HadGEM2-AO at preindustrial (blue), $2 \times \mathrm{CO}_{2}$ (brown) and $12544 \times \mathrm{CO}_{2}$ (red); (d) box model calibrated to Smith et al. [2007] ocean reanalyses for the 1255 decades 1979-89 (black), 1989-99 (cyan), 2000-2009 (blue). 
a.

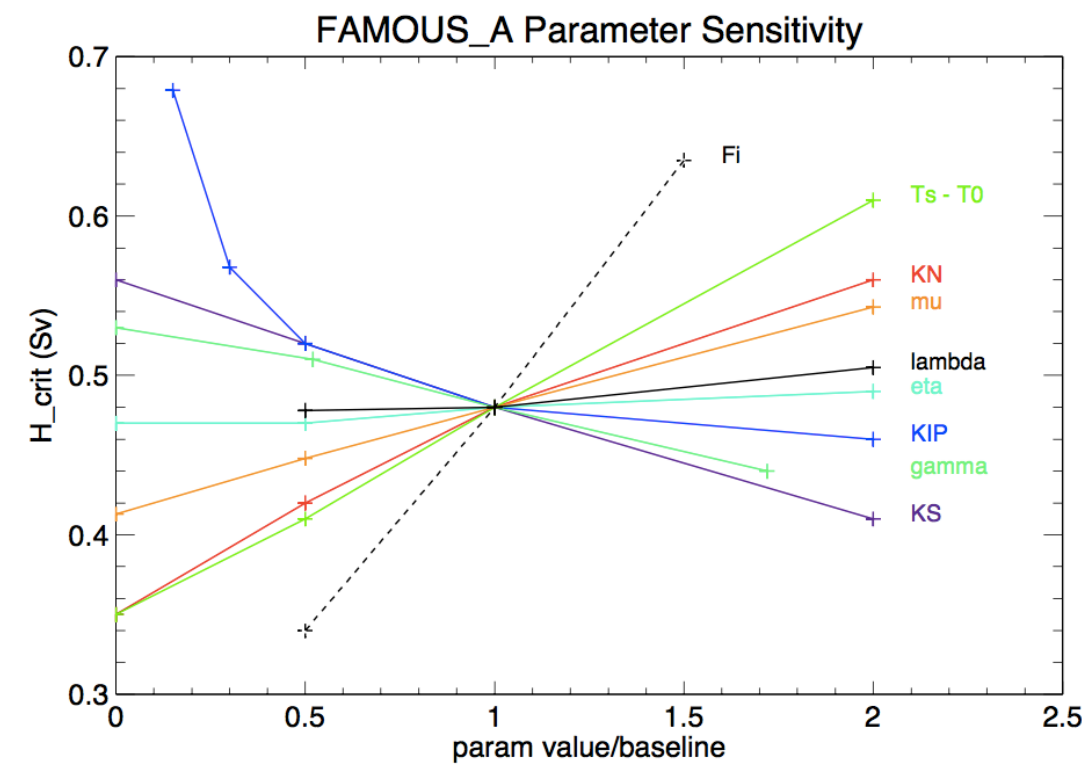

1258

1259

b.

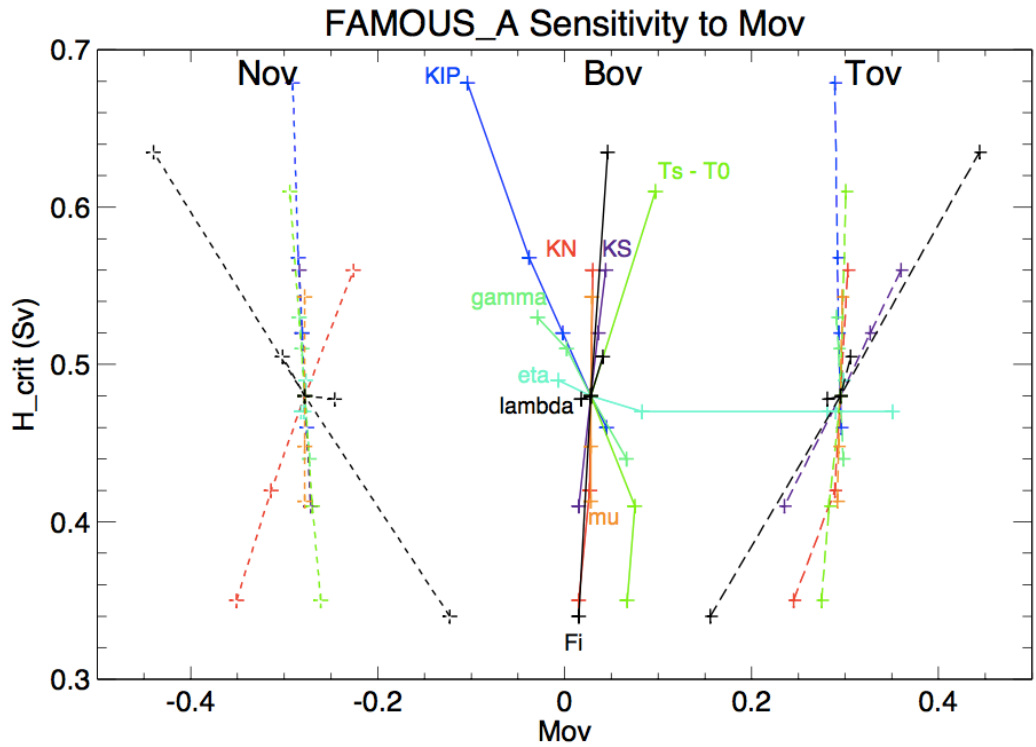

Fig. 6. Sensitivity of $\mathrm{H}_{\text {crit }}$ to box model parameters

1262 (a) Sensitivity of $H_{\text {crit }}$ to changes in the values of a single box model parameter, relative to a 1263 baseline state calibrated to the FAMOUS $_{\mathrm{A}}$ AOGCM experiment. The baseline parameter 1264 values are given in Table 1, and the parameter changes are shown along the horizontal axis 1265 as a proportion of the baseline value.

1266 (b) For same box model parameter sensitivity experiments as in (a), sensitivity of $H_{\text {crit }}$ to the 1267 value of the fresh water transport by the AMOC (Sv) in the un-hosed state, for the three 1268 diagnostics $N_{O V}$ (short dashed, left), $T_{O V}$ (long dashed, right) and $B_{O V}$ (solid, centre) - units: 1269 Sv. 


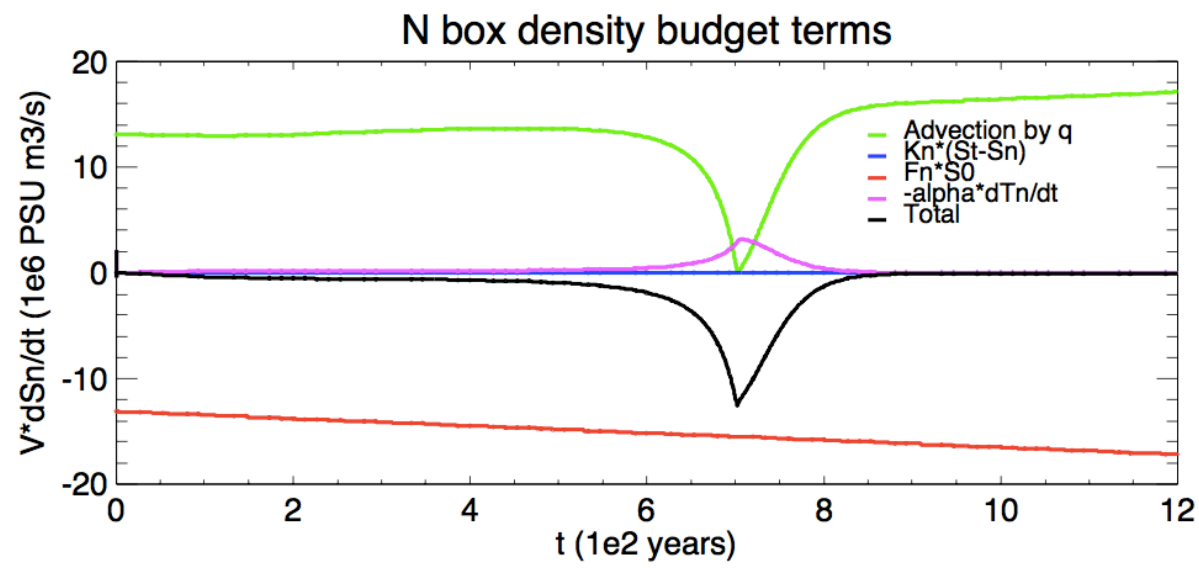

1271

1272

b.

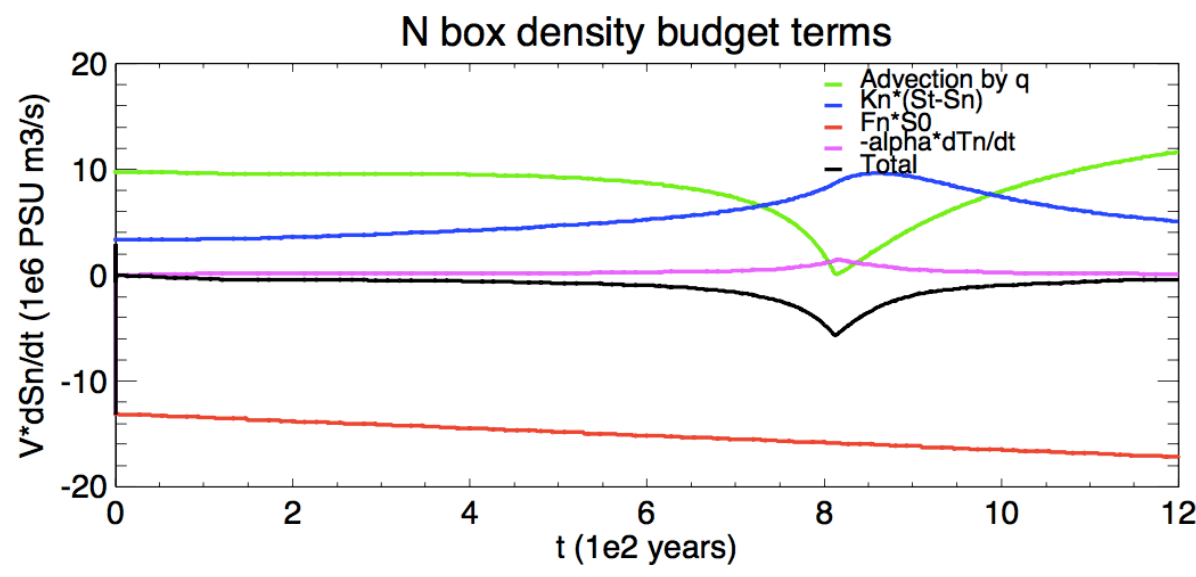

1273

1274

c.

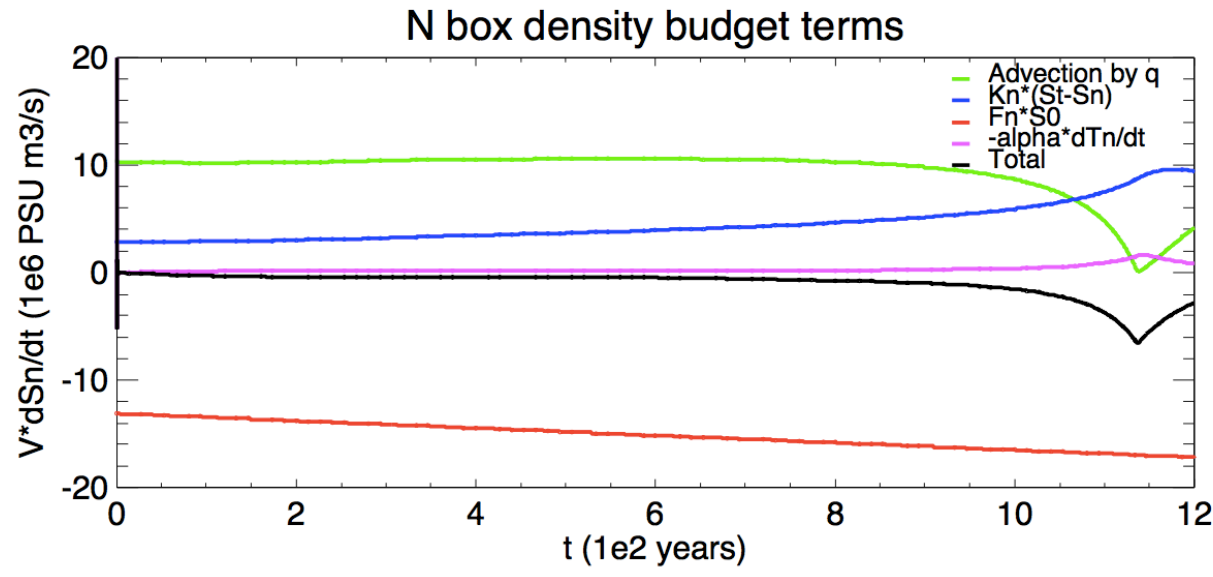

1275

\section{$1276 \quad$ Fig. 7}

$1277 \mathrm{~N}$ box salinity budget for selected box model parameter sensitivity tests relative to the

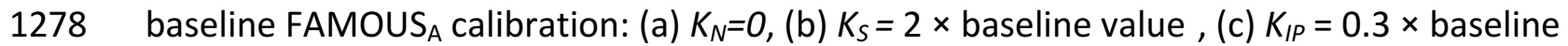
1279 value. Legend as for Fig. 4b. 


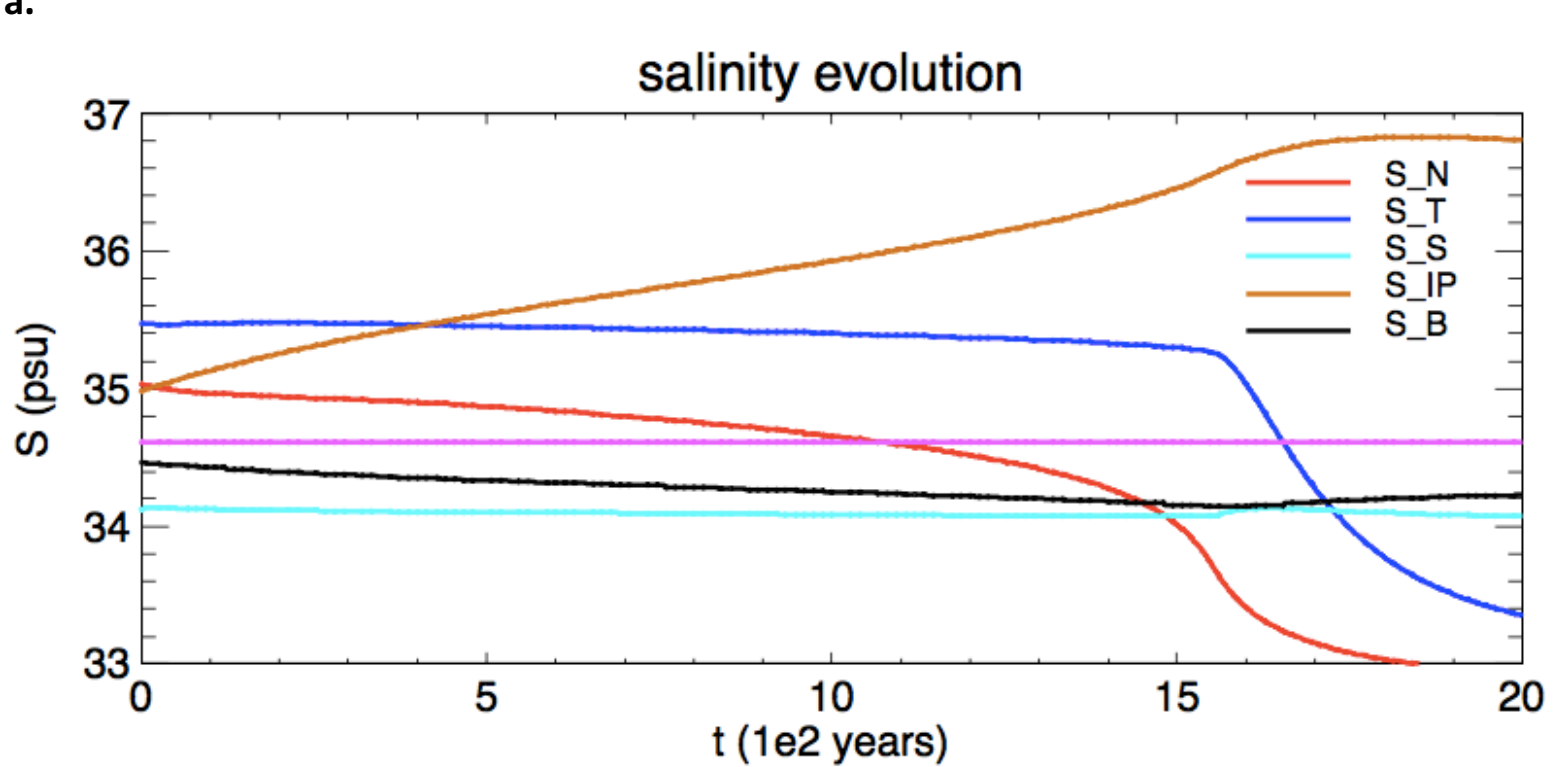

1283

b.

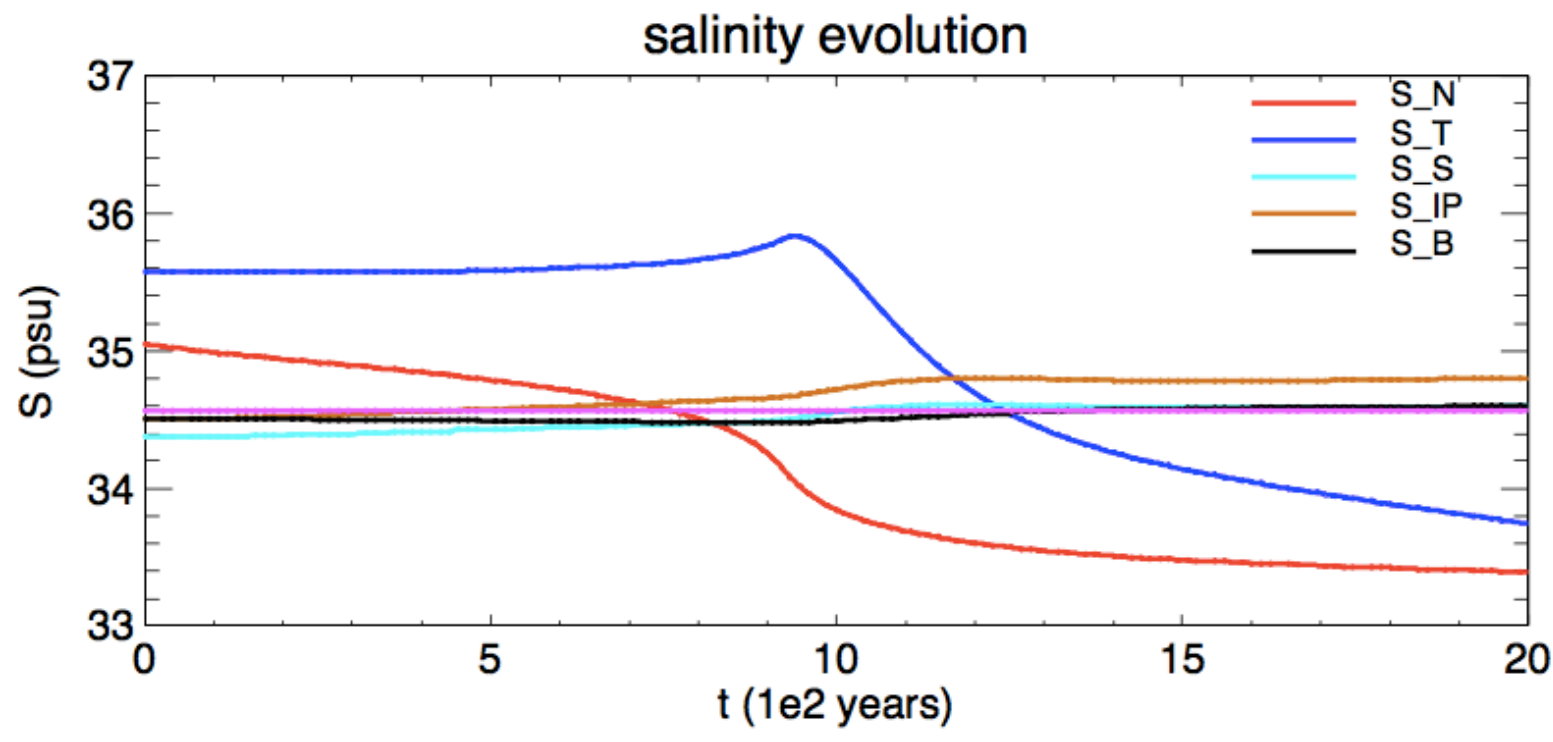

1285

1286

$1287 \quad$ Fig. 8

1288 Box model salinity evolution over the ramp-up stage in the parameter sensitivity studies for 1289

(a) $K_{I P}=8.9778 \mathrm{~Sv}\left(0.1 \times\right.$ baseline value) and (b) $K_{I P}=179.556 \mathrm{~Sv}(2 \times$ baseline value).

1290 
a.

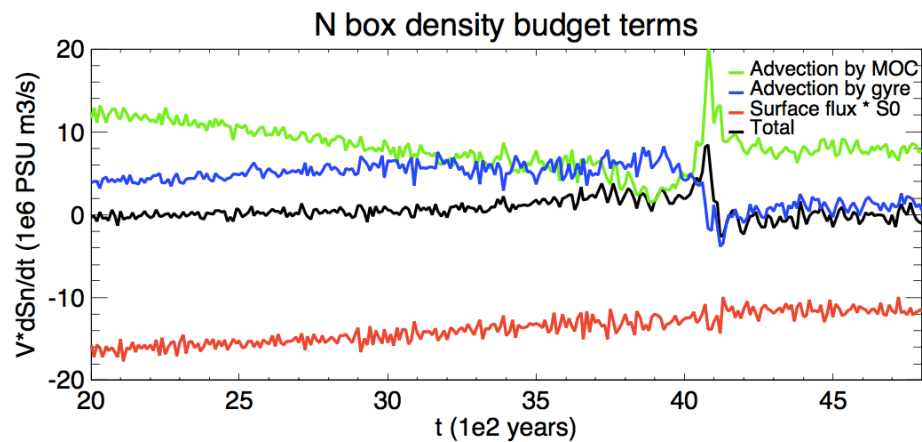

1293

1294

b.

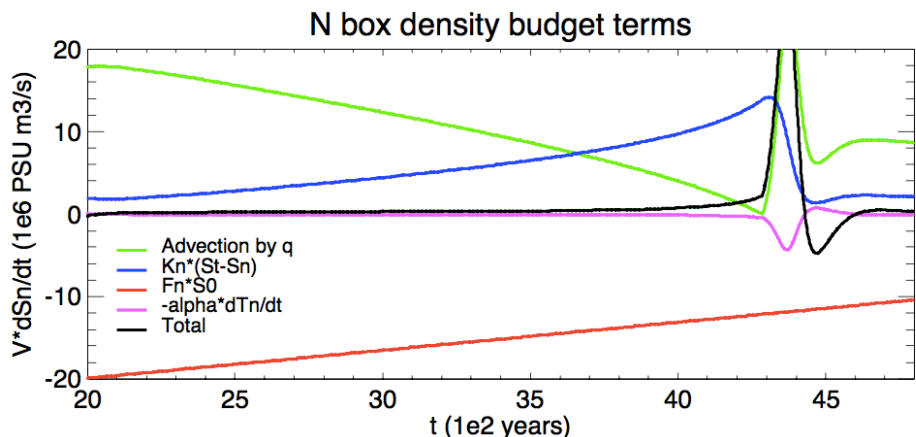

1295

1296

c.

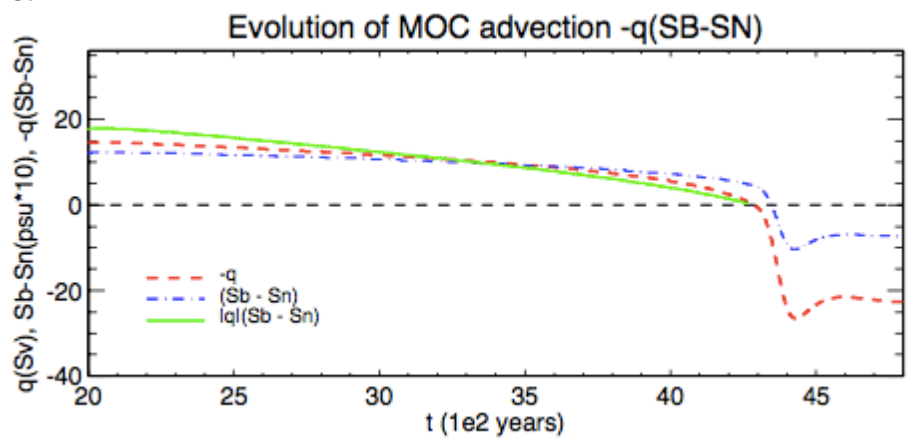

1297

1298

1299

Fig. 9

1300 As Fig. 4, but for the ramp-down phase from year $2000(H=1.0 \mathrm{~Sv})$ to year $4800(H=-0.4$ 1301 Sv). 


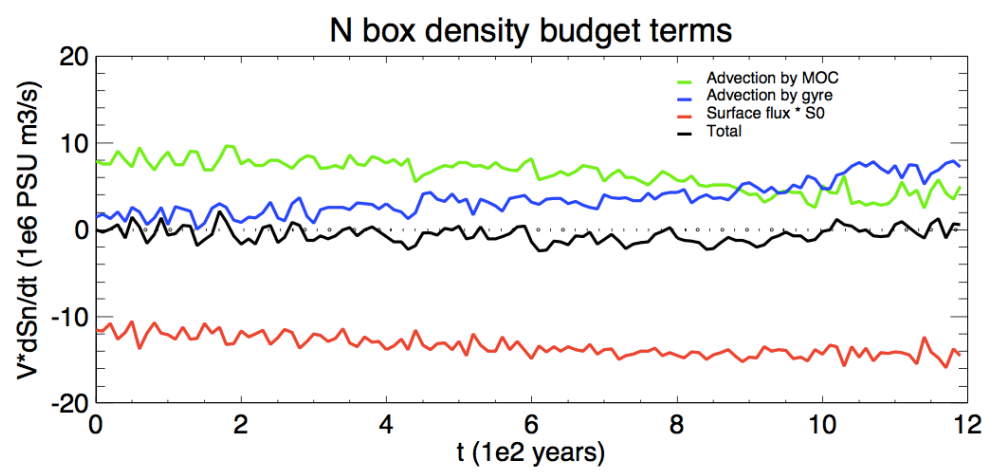

1304

b.

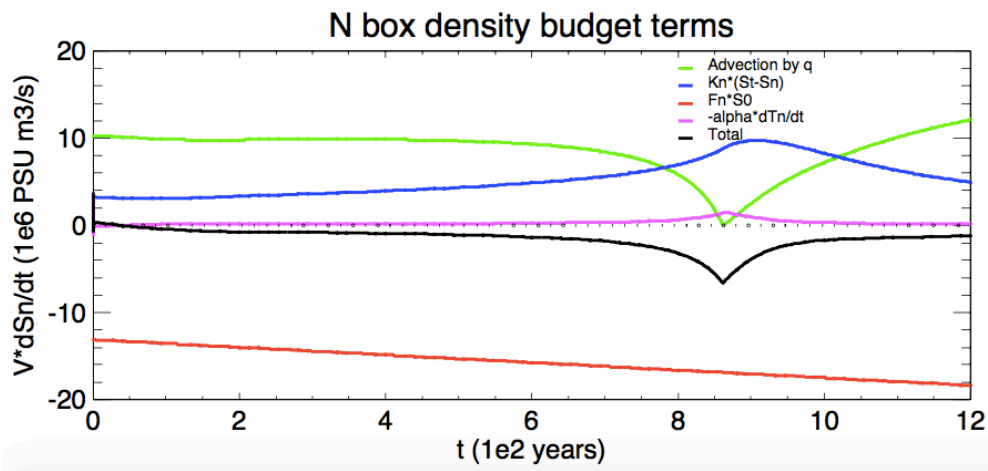

1305

C

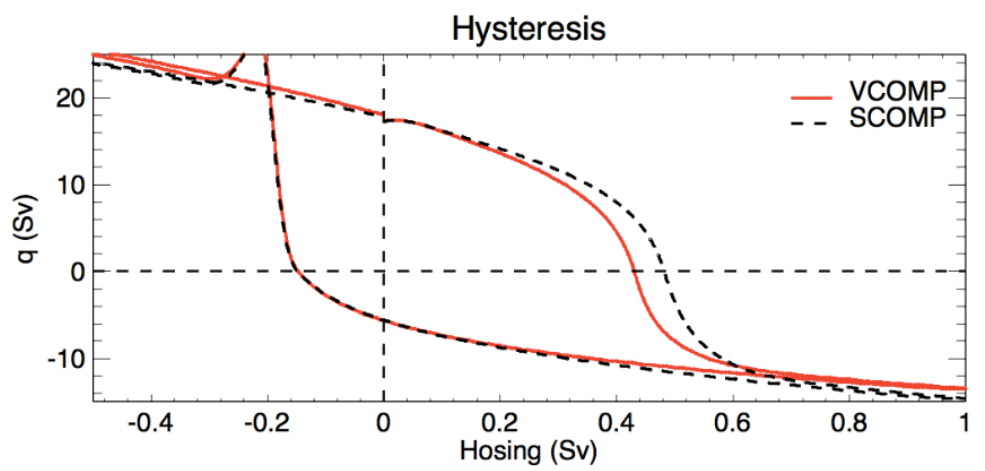

Fig. 10

AMOC hysteresis in the VCOMP version of FAMOUS $_{A}$ and the corresponding box model. Shown in (a) and (b) are the FAMOUS $_{\mathrm{A}}$ and box model salinity budgets for the $\mathrm{N}$ box in the ramp-up phase (cf. Fig. 4 a,b for SCOMP), while (c) shows the whole hysteresis loop (red), with the corresponding loop from the SCOMP run in black dashed (reproduced from Fig. 3c) 